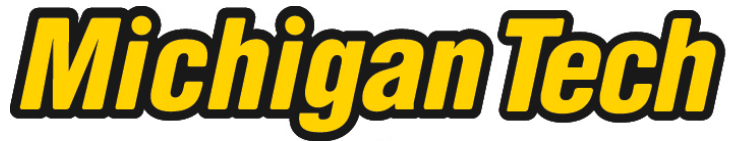 \\ Michigan Technological University Create the Future Digital Commons @ Michigan Tech
}

Dissertations, Master's Theses and Master's Reports - Open

Dissertations, Master's Theses and Master's

Reports

2011

Sediment yield reduction in an agricultural watershed

Lijun Chen

Michigan Technological University

Follow this and additional works at: https://digitalcommons.mtu.edu/etds

Part of the Civil and Environmental Engineering Commons

Copyright 2011 Lijun Chen

\section{Recommended Citation}

Chen, Lijun, "Sediment yield reduction in an agricultural watershed", Master's Thesis, Michigan

Technological University, 2011.

https://doi.org/10.37099/mtu.dc.etds/227

Follow this and additional works at: https://digitalcommons.mtu.edu/etds

3 Part of the Civil and Environmental Engineering Commons 


\title{
SEDIMENT YIELD REDUCTION IN AN AGRICULTRUAL WATERSHED
}

By

Lijun Chen

\begin{abstract}
A THESIS
Submitted in partial fulfillment of the requirements for the degree of MASTER OF SCIENCE

(Environmental Engineering)
\end{abstract}

MICHIGAN TECHNOLOGICAL UNIVERSITY

2011

(C) 2011 Lijun Chen 
This thesis, "Sediment Yield Reduction in an Agricultural Watershed," is hereby approved in partial fulfillment of the requirements for the Degree of MASTER OF SCIENCE IN ENVIRONMENTAL ENGINEERING.

Department of Civil and Environmental Engineering

Signatures:

Thesis Advisor

Brian Barkdoll

Committee Member

Ann Maclean

Committee Member

Alex Mayer

Department Chair

David Hand

Date 


\section{Table of Contents}

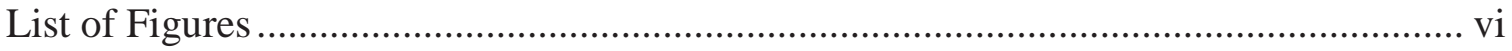

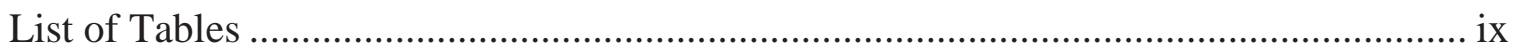

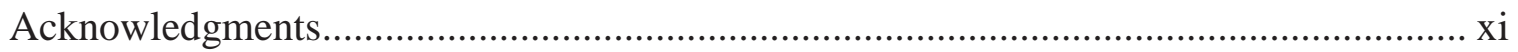

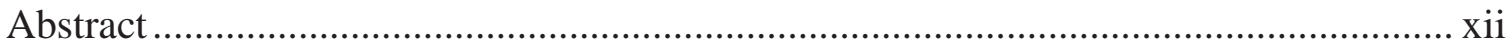

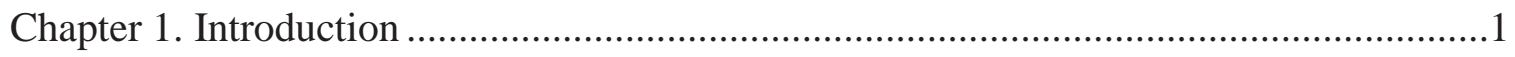

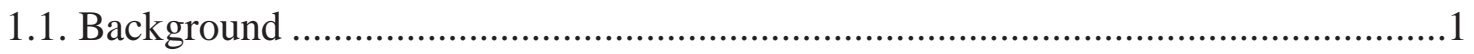

1.2. Study Objectives .......................................................................................

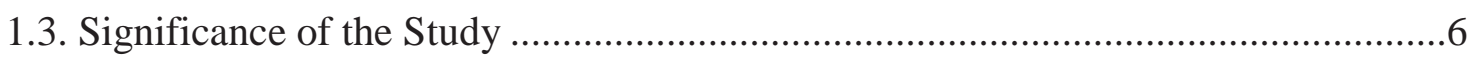

Chapter 2. Background: Study Area, SWAT, and BMPs Applied ..................................

2.1. Study Area for Method Demonstration ............................................................

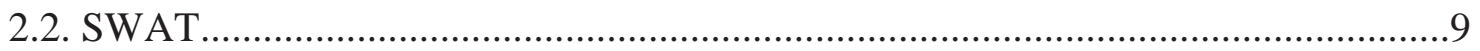

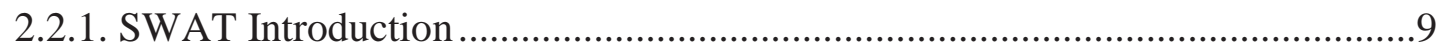

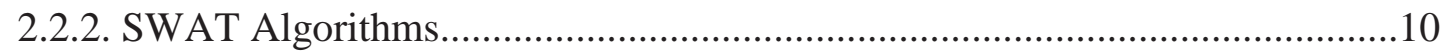

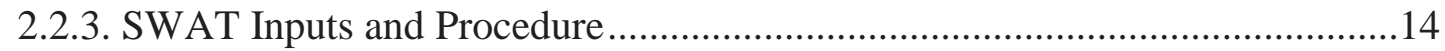

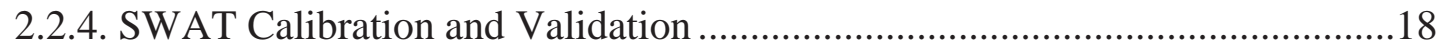

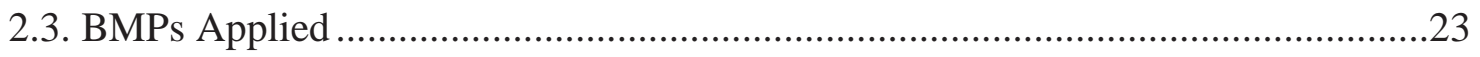

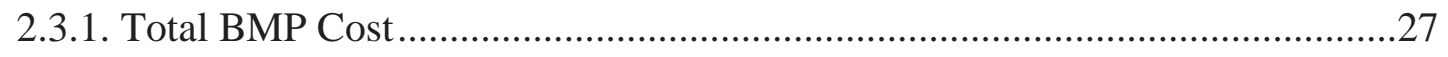

Chapter 3. BMP Number and Placement Selection by Targeting ................................29

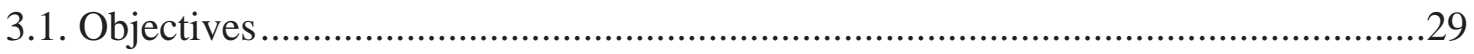

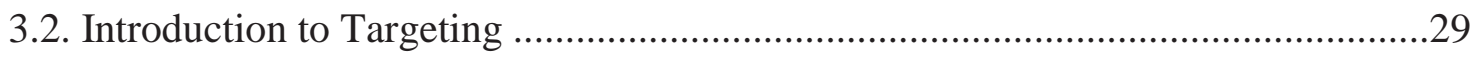


3.3. Procedure of Targeting.

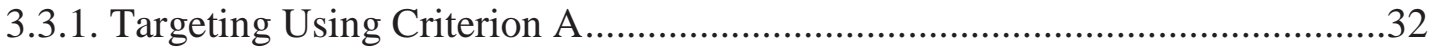

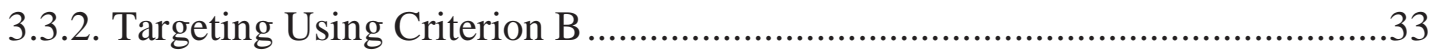

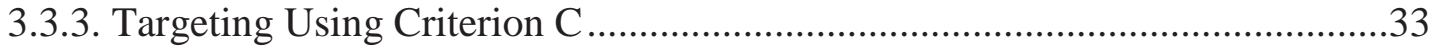

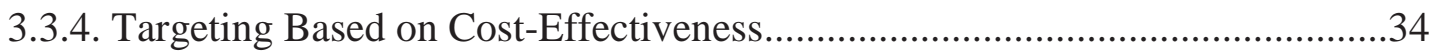

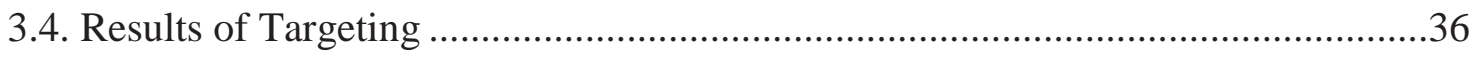

3.4.1. Results of Targeting for the Filter Strip Application....................................36

3.4.2. Results of Targeting for the Grassed Waterway Application.........................42

3.4.3. Results of Targeting Based on Cost-Effectiveness ......................................44

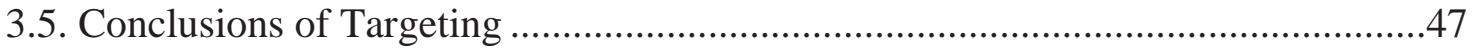

Chapter 4. BMP Number and Placement Optimization by a Genetic Algorithm.............48

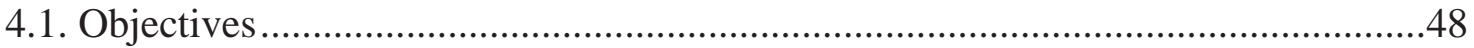

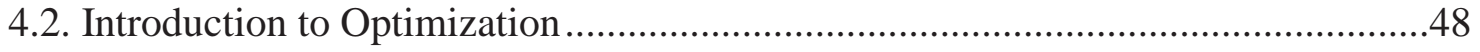

4.2.1. Non-dominated Sorting Genetic Algorithm II ...........................................48

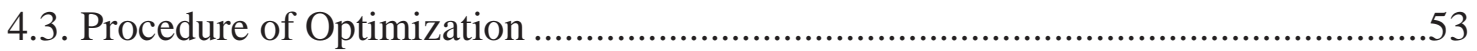

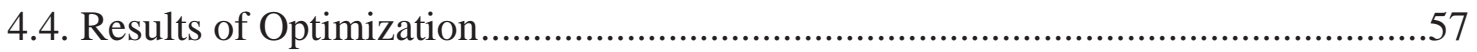

Chapter 5. Comparison of Targeting and Optimization Methods..................................62

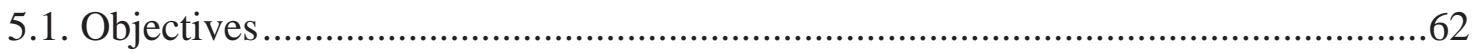

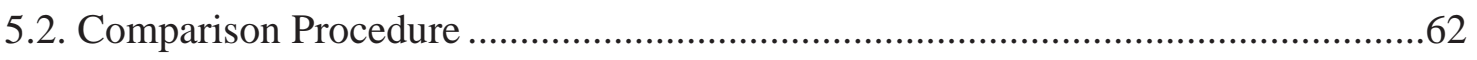

5.2.1. Solution of Targeting and Optimization Methods......................................62 
5.2.2. Computational Times of Targeting and Optimization Methods.

5.2.3. Uncertainty of Targeting and Optimization Methods ..................................70

5.3. Conclusions of the Compasion of Targeting and Optimization Methods ...............71

Chapter 6. Application of the Targeting Based on Cost ..............................................72

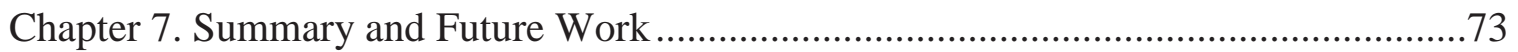

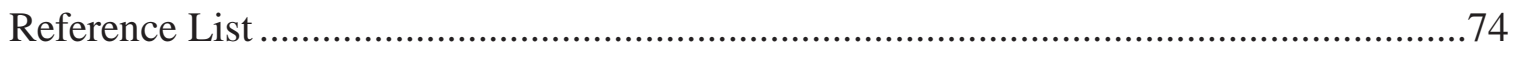

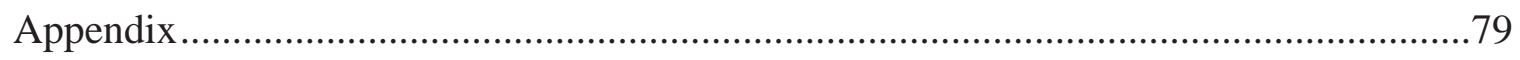




\section{List of Figures}

Figure 1.1. Flowchart of this study.

Figure 2.1. Location of EB Coon Creek Watershed in MI, figure by author using

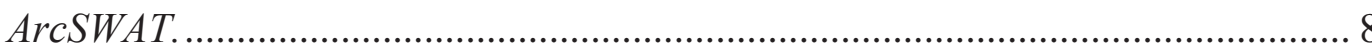

Figure 2.2. Locations for USGS gage and weather stations, figure by author using

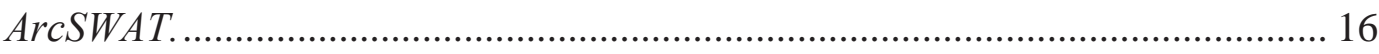

Figure 2.3. Modeling procedure of SWAT demonstrated on EB Coon Creek Watershed. 17

Figure 2.4. Before and after one sub-watershed was defined as one HRU. 18

Figure 2.5. Daily precipitation for this study. 22

Figure 2.6. Daily flow at the watershed outlet for this study. 23

Figure 2.7. Filter Strip. Photo by EPA.

http://web.epa.ohio.gov/dsw/nps/NPSMP/FUND/fundusda.html. 4/24/2011..... 24

Figure 2.8. Grassed Waterway. Photo by Charlie Rahm, USDA Natural Resources Conservation Service. http://www.ers.usda.gov/Amberwaves/September04/Features/measuringsuccess.ht m. 4/24/2011 24

Figure 3.1. Outline of targeting 32

Figure 3.2. Effect of watershed BMP coverage on sediment yield for Results $A, B$, and $C$. 40 
Figure 3.3. Sub-watersheds for filter strip placement, chosen based on different criteria.

Figure 3.4. Location of main channel segments that are sediment deposition-dominant. 42

Figure 3.5. Main channel segments for grassed waterway placement, chosen based on

Criterion $C$

Figure 3.6. The targeting result based on cost-effectiveness. BMPs selected are 5-m filter strips and grassed waterways. 46

Figure 4.1. Crossover in a binary $G A$. 50

Figure 4.2. Mutation in a binary $G A$ 50

Figure 4.3. Flowchart of the NSGA-II. 56

Figure 4.4. Comparison between the pseudo Pareto front at the last generation of NSGAII using different total generations. 60

Figure 4.5. Pseudo Pareto front at the last generation of NSGA-II with 150 total generations 61

Figure 5.1. Comparison between targeting and NSGA-II (full results). 66

Figure 5.2. Comparison between targeting and NSGA-II (partial results, in order to show the difference beween targeting and NSGA-II more clearly).

Figure 5.3. Comparison between targeting and NSGA-II with different total generations. 
Figure 6.1. Results of BMP (5-m filter strips and grassed waterways) allocation from

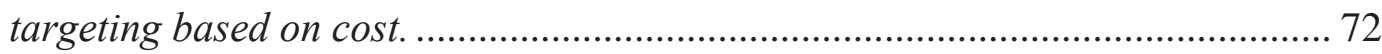




\section{List of Tables}

Table 2.1. Land use distribution in EB Coon Creek Watershed, from National Land Cover Data 2001 (SWAT variable name in parentheses)

Table 2.2. SWAT inputs and sources 15

Table 2.3. Ranking of the sensitive SWAT input parameters for the watershed outlet discharge. The higher the ranking, the more sensitive the parameter. 19

Table 2.4. SWAT parameters selected for calibration 21

Table 2.5. Information and results for the SWAT calibration and validation, and value greater than 0.5 is acceptable (Moriasi et al. 2007) 21

Table 2.6. SWAT representations of filter strip and grassed waterway 26

Table 2.7. BMP Costs, attained from USDA and NRCS*..... 27

Table 3.1. Description of each targeting criterion 31

Table 3.2. Meaning of $\triangle S Y$ for different criteria 35

Table 3.3. Result A for filter strips 38

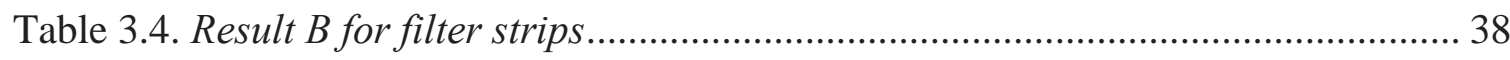

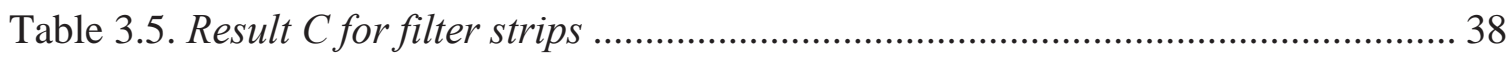

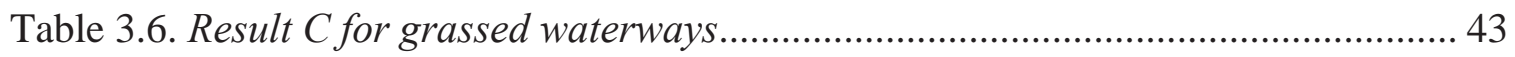

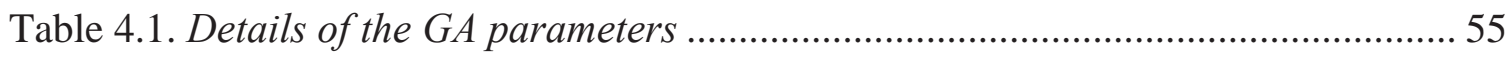
ix 
Table 5.1. Comparison of the computational time for targeting and NSGA-II.

Table A.1. Rank A for filter strips............................................................................. 79

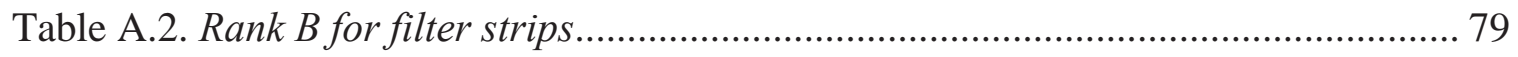

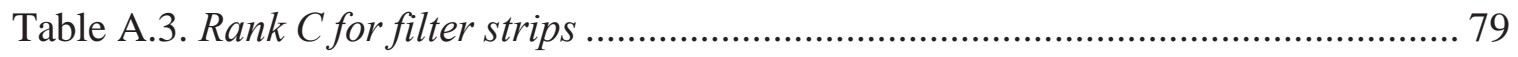

Table A.4. Rank C for grassed waterways ................................................................. 79

Table A.5. 4-yr average difference between SEDIN and SEDOUT for each main channel

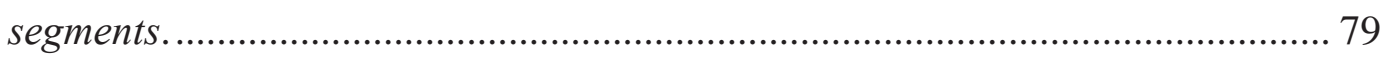

Table B.1. CErank for both filter strips and grassed waterways ................................... 79

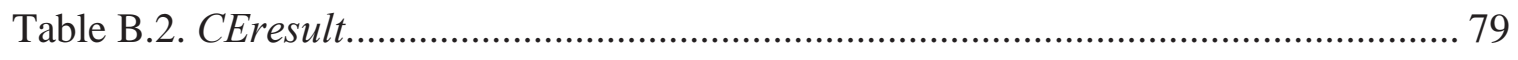

Table C.1. Results of the last generation of NSGA-II with different total generations. ... 80

Table D.1. Non-domination of solutions from both targeting and NSGA-II. ................... 80

Table E.1. Explanations for the term used in this study............................................. 80 


\section{Acknowledgments}

I would like to express my gratitude to my advisor Dr. Brian Barkdoll for providing suggestion, guidance, inspiration, and support throughout this degree. Also, I appreciate the time that my other committee members Dr. Ann Maclean and Dr. Alex Mayer have devoted for providing all those insightful comments.

My special thanks to my family who has been encouraging me since the day I was born. 


\section{Abstract}

With proper application of Best Management Practices (BMPs), the impact from the sediment to the water bodies could be minimized. However, finding the optimal allocation of BMP can be difficult, since there are numerous possible options. Also, economics plays an important role in BMP affordability and, therefore, the number of BMPs able to be placed in a given budget year. In this study, two methodologies are presented to determine the optimal cost-effective BMP allocation, by coupling a watershed-level model, Soil and Water Assessment Tool (SWAT), with two different methods, targeting and a multi-objective genetic algorithm (Non-dominated Sorting Genetic Algorithm II, NSGA-II). For demonstration, these two methodologies were applied to an agriculture-dominant watershed located in Lower Michigan to find the optimal allocation of filter strips and grassed waterways. For targeting, three different criteria were investigated for sediment yield minimization, during the process of which it was found that the grassed waterways near the watershed outlet reduced the watershed outlet sediment yield the most under this study condition, and cost minimization was also included as a second objective during the cost-effective BMP allocation selection. NSGA-II was used to find the optimal BMP allocation for both sediment yield reduction and cost minimization. By comparing the results and computational time of both methodologies, targeting was determined to be a better method for finding optimal costeffective BMP allocation under this study condition, since it provided more than 13 times the amount of solutions with better fitness for the objective functions while using less 
than one eighth of the SWAT computational time than the NSGA-II with 150 generations did. 


\section{Chapter 1. Introduction}

\subsection{Background}

Every year in North America around 6 billion tons of sediment erodes, leading to $\$ 16$ billion in damages (Osterkamp et al. 1998). As one of the top ten reasons for the impairment in assessed water bodies in the United States, the possible adverse effects from sediment to water resources relate to both water quantity as well as water quality (EPA 2004). Firstly, in regards to water quantity, sedimentation could restrict the capacity of culverts, canals, reservoirs, streams, lakes and other water bodies. By 1986 almost one-fifth of the storage capacity of the world's reservoirs had been filled by around 1,100 cubic kilometers of sediment (McCully 1996). In the United States, large reservoirs lose their storage capacity at an average rate of $0.2 \%$ annually (McCully 1996). Secondly, water quality is also affected, evidenced by suspended sediment and the attached pollutants resulting in the degradation of the aquatic environment such as reduction of light penetration, and decrease of fish growth rate (Wood and Armitage 1997).

The impact from the sediment to water bodies and structures could be minimized by proper application of Best Management Practices (DEQ 2011). Best Management Practices (BMPs) are implementations designed to treat, prevent or reduce water pollution (DEQ 2011). The performances of BMPs can be measured using mathematical models (DEQ 2011). Different watershed-scale models such as the Annualized Agricultural Nonpoint Source model (AnnAGNPS) (Bingner et al. 2009), Nonpoint 
Source Watershed Environment Response Simulation-2000 (ANSWERS-2000)

(Bouraoui and Dillaha 1996), and Soil and Water Assessment Tool (SWAT) (Neitsch et al. 2005) have been applied to decide the number and placement of BMPs (Niu et al. 2001, Parajuli et al. 2008, Srivastava et al. 2002). Compared with other models, SWAT has been proven to be a robust model suitable for assessing long-term hydrological changes and agricultural watershed management practices (Borah and Bera 2003, Parajuli et al. 2009, Saleh and Du 2004).

With the help of a model, especially a watershed-scale model, it is easy to evaluate BMPs performances across the watershed level; however, finding the optimal number and placement of the BMPs can be difficult, since there are numerous possible options. For instance, if there are 50 possible locations for BMPs in the watershed, the possible implementation options are $2^{50}$ for only 1 type of BMP. There will be even more possibilities if there are more location choices and more BMP candidates. There are two categories of methods for finding the optimal BMP placement and numbers across a watershed, namely targeting (ranking according to some criteria) and optimization (modeling a carefully-selected subset of possibilities and choosing the options most desirable) (Arabi et al. 2006, Parajuli et al. 2008, Srivastava et al. 2002, Tuppad et al. 2010). Both of these methods evaluate a limited number of possible combinations of BMP since it would take an infeasible amount of computational time to perform complete enumeration in which all possible combinations and permutations are calculated. For the watershed used in this study (described in detail later) the total number of BMP combination is $2^{416}=1.69^{*} 10^{125}$. To evaluate the performance of these possible 
realizations, it will require the running of a simulation model (SWAT in this study) that can take approximately 1 minute of computation time for each evaluation, resulting in a total computation time for complete enumeration of $3.22 * 10^{119}$ years. This infeasible computation time means that a method is needed that can yield a pseudo optimal result in a reasonable computation time, such as those two methods used here.

Targeting aims to install the BMP in the most critical areas. Targeting consists of ranking each of the possible BMP locations using some criteria to decide which locations are the most critical areas to implement the BMPs. Typically the sediment yield per hectare from a sub-watershed has been used as the single criterion for BMP location selection (Parajuli et al. 2008, Tuppad et al. 2010). When compared to a random selection of BMP locations, targeting using this criterion performed well (Parajuli et al. 2008, Tuppad et al. 2010). It remains to be seen; however, how targeting based on this typical criterion will perform when compared to other criterion. Also, economics plays an important role in BMP affordability and, therefore, the number of BMPs able to be placed in a given budget year. Even though targeting is an easy and effective way to decide BMP allocation, targeting only considers the effect of each BMP individually, and not the spatial interaction among them, thereby missing a less expensive or effective BMP placement combination is possible.

Another method for finding the optimal BMP number and placement is optimization which applies mathematical programming to select the best option from a set of available candidates. Well known examples of optimization algorithms are Hill Climbing, Genetic Algorithms, and Ant Colony optimization. 
When solving an optimization problem, it is common that there are not only one but several objectives which may conflict with each other. For example, in an environmental area, it is desirable to maximize pollution reduction while minimizing management practice costs. This multi-objective problem can be handled with a single or multiobjective optimization algorithm. For the single-objective optimization algorithm, only one objective is optimized while constraints are placed on others. This leads to a single pseudo-optimal solution under these specified constraints. The solution is considered to be "pseudo" optimal because only by complete enumeration (trying every possible combination and permutation of possible solution) can the true optimal solution be found. In contrast, the multi-objective optimization algorithm models all objectives simultaneously, hence providing what is termed the pseudo Pareto front which consists of a group of pseudo Pareto optimization results (values of the objective functions, i.e., sediment yield or cost, plotted against each other). The pseudo Pareto front can be used to choose an optimal solution. A multi-objective evolutionary algorithm (MOEA) is among the most popular multi-objective optimization algorithms, since it deals with discontinuous and concave Pareto fronts easily (Coello Coello 2006). Evolutionary algorithms are those based on the logic of evolution theory in which only the fittest solutions survive, each new "generation" being combinations of "parents" of a previous generation. This will be described in more detail later. Among the MOEA methods, the Non-dominated Sorting Genetic Algorithm II (NSGA-II) has been proven to be a better algorithm when compared to other kinds of MOEA (Deb et al. 2002). The "Nondominated Sorting" means that the solution better fulfilling at least one objective function will be selected by NSGA-II. 
Optimization can be computationally intensive, however, since it will need to call the watershed simulation model to evaluate the fitness for every selected candidate solution (Arabi et al. 2006). To reduce the computation time, it is possible to record the results of smaller watershed components (e.g. sub-watersheds or hydrologic response units, HRUs, which are used in SWAT)) and refer to them in subsequent simulation runs instead of repeatedly running the watershed simulation model (Maringanti et al. 2009). However, if results of sediment yield from a sub-watershed are used for subsequent simulation runs, there is no information gathered about sediment yield from the entire watershed. Hence, it is unclear if optimizing based on individual sub-watershed results will result in minimal sediment yield for the entire watershed.

Since targeting and optimization have their own advantages, it is necessary to compare the two methods to aid modelers in BMP placement selection to minimize cost and sediment yield.

\subsection{Study Objectives}

This study determines the optimal BMP number and placement with two different methods: targeting and NSGA-II (Figure 1.1). For targeting, three different criteria were investigated for sediment yield minimization and their results compared. Next, targeting based on cost-effectiveness was used to find the most cost-effective BMP allocation. NSGA-II was used to find the optimal BMP allocation for both sediment yield reduction and cost minimization. The NSGA-II resulted in the pseudo Pareto front, which provides the pseudo-optimal solutions for different objective functions values. Finally, the results 
and computational time of targeting and NSGA-II were compared to decide which method is more computationally efficient under these study conditions.

\subsection{Significance of the Study}

The comparison between the targeting method and the NSGA-II helps modelers in BMP placement selection to minimize cost and sediment yield. The optimal placement of BMPs will aid decision makers in reducing sediment yield from a watershed and perhaps aid in the determination of Total Maximum Daily Loads (TMDLs) to meet the desired water quality standard goals for impaired water bodies. 


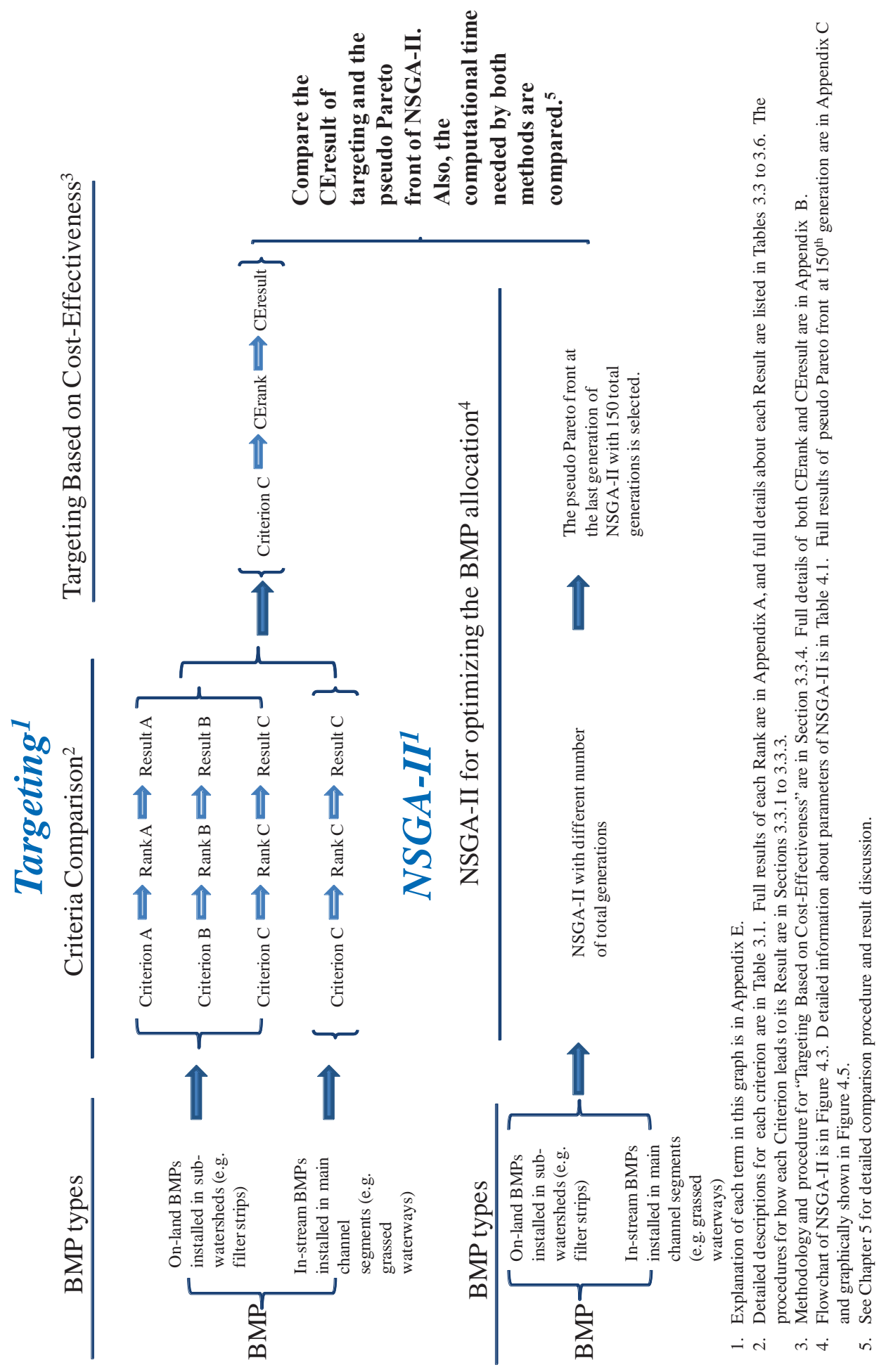

Figure 1.1. Flowchart of this study. 


\section{Chapter 2. Background: Study Area, SWAT, and BMPs}

\section{Applied}

\subsection{Study Area for Method Demonstration}

Two methods for optimal placement of BMPs are presented here. For demonstration of the newly proposed methods, the East Branch Coon Creek Watershed (EB Coon Creek Watershed) (AUID: 040900030303-01), which is located at the boundary of St. Clair and Macomb Counties in Lower Michigan (Figure2.1), was employed. The total area of this 59\%-agricultural watershed is 3345.49 ha (Table 2.1).

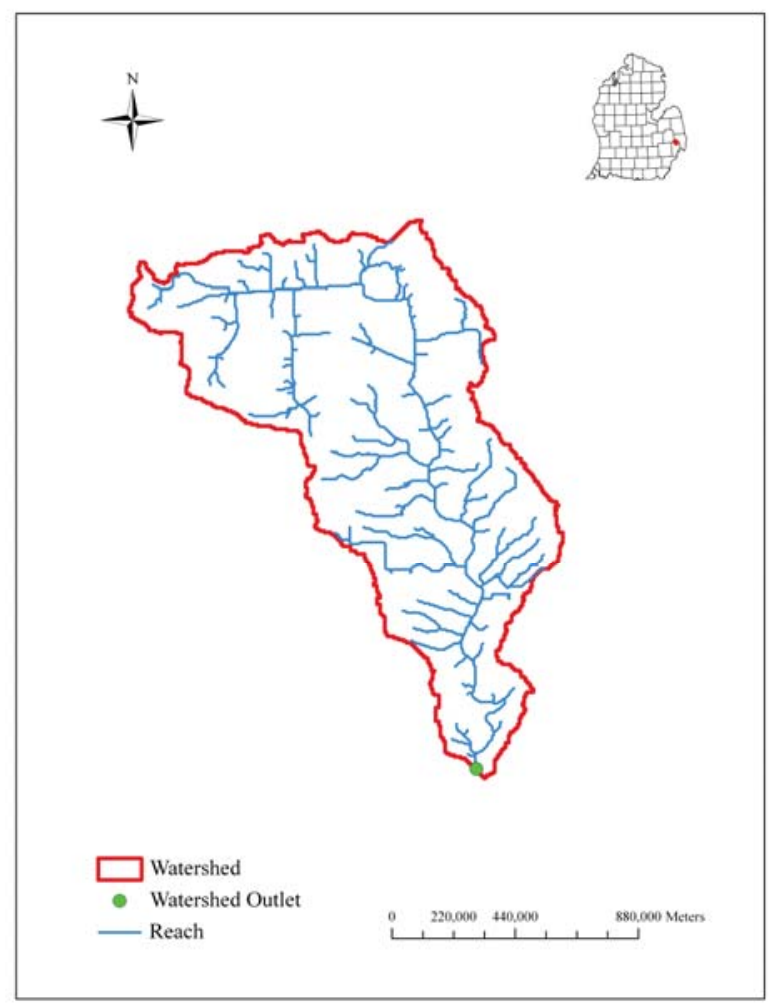

Figure 2.1. Location of EB Coon Creek Watershed in MI, figure by author using ArcSWAT. 
Table 2.1. Land use distribution in EB Coon Creek Watershed, from National Land Cover Data 2001 (SWAT variable name in parentheses)

\begin{tabular}{|c|rr|}
\hline Landuse & Area [ha] & \% total Area \\
\hline Agricultural Land-Row Crops (AGRR) & 1980.83 & 59.21 \\
Hay (HAY) & 557.63 & 16.67 \\
Forest-Deciduous (FRSD) & 251.90 & 7.53 \\
Wetlands-Forested (WETF) & 219.60 & 6.56 \\
Residential-Medium Density (URMD) & 127.69 & 3.82 \\
Residential-Low Density (URLD) & 109.49 & 3.27 \\
Range-Grasses (RNGE) & 31.32 & 0.94 \\
Wetlands-Non-Forested (WETN) & 24.72 & 0.74 \\
Residential-High Density (URHD) & 15.17 & 0.45 \\
Range-Brush (RNGB) & 10.16 & 0.30 \\
Southwestern US (Arid) Range (SWRN) & 7.28 & 0.22 \\
Forest-Mixed (FRST) & 4.63 & 0.14 \\
Industrial (UIDU) & 4.32 & 0.13 \\
Forest-Evergreen (FRSE) & 0.76 & 0.02 \\
\hline & 3345.49 & 100.00 \\
\hline
\end{tabular}

\subsection{SWAT}

\subsubsection{SWAT Introduction}

Soil and Water Assessment Tool (SWAT) is a basin-scale, continuous simulation model, designed for prediction of the impact of management on water, sediment, and agricultural chemical loading in gauged or ungauged watershed (Neitsch et al. 2005). This physically-based, daily time step model is suitable for long-term simulation in agricultural watersheds, but not capable for single-event routing (Borah and Bera 2003). The major model components are climate, hydrology, land cover/plant growth, sedimentation, nutrients, pesticides, and agricultural management. For watershed simulation using SWAT, a watershed is divided into sub-watersheds, each of which is further grouped into different hydrologic response units (HRUs). HRUs are lumped land 
areas with unique combinations of land use, soil and management practice. After HRUs are formed, the daily water budget in each HRU is calculated based on the balance between precipitation, runoff, evapotranspiration, percolation, subsurface flow, and ground water flow.

\subsubsection{SWAT Algorithms}

Surface runoff can be computed based on the Green and Ampt infiltration equation or the Soil Conservation Service (SCS) runoff curve number method (Eq. 1) (SCS 1972) (selected in this study).

$$
Q_{\text {surf }}=\frac{\left(R_{d a y}-I_{a}\right)^{2}}{\left(R_{d a y}-I_{a}+S\right)}
$$

Where,

$Q_{\text {surf }}=$ Accumulated runoff of rainfall excess $\left(\mathrm{mm} \mathrm{H}_{2} \mathrm{O}\right)$;

$R_{\text {day }}=$ Rainfall depth for the day $\left(\mathrm{mm} \mathrm{H}_{2} \mathrm{O}\right)$;

$I_{a}=$ Initial abstractions which includes surface storage, interception and infiltration

prior to runoff $\left(\mathrm{mm} \mathrm{H}_{2} \mathrm{O}\right)$. Commonly, $I_{a}$ is approximated as $0.2 \mathrm{~S}$;

$S=$ Retention parameter $\left(\mathrm{mm} \mathrm{H}_{2} \mathrm{O}\right)$, which is defined using Eq. 2.

$$
S=25.4\left(\frac{1000}{C N}-10\right)
$$

Where,

$C N=$ Curve number for the day. This parameter is decided by the permeability of soil, land use, and antecedent soil water conditions.

The erosion caused by rainfall and runoff is estimated using the Modified Universal Soil Loss Equation (MUSLE) (Eq. 3) (Williams 1995). 


$$
\text { sed }=11.8 \cdot\left(Q_{\text {surf }} \cdot q_{\text {peak }} \cdot \text { area }_{\text {hru }}\right)^{0.56} \cdot K_{U S L E} \cdot C_{U S L E} \cdot P_{U S L E} \cdot L S_{U S L E} \cdot C F R G
$$

Where,

sed $\quad=$ Sediment yield on a given day (metric tons);

$Q_{\text {surf }}=$ Surface runoff volume $\left(\mathrm{mm} \mathrm{H}_{2} \mathrm{O} / \mathrm{ha}\right)$;

$q_{\text {peak }}=$ Peak runoff rate $\left(\mathrm{m}^{3} / \mathrm{s}\right)$;

$\operatorname{area}_{h r u}=$ Area of the HRU (ha);

$K_{U S L E}=$ USLE soil erodibility factor $\left(0.013\right.$ metric ton $\mathrm{m}^{2} \mathrm{hr} /\left(\mathrm{m}^{3}\right.$-metric ton $\left.\left.\mathrm{cm}\right)\right)$;

$C_{U S L E}=$ USLE cover and management factor;

$P_{U S L E}=$ USLE support practice factor;

$L S_{U S L E}=$ USLE topographic factor;

$C F R G=$ Coarse fragment factor.

During the flow routing in each channel segment, Manning's equation for uniform flow is applied to calculate the velocity of flow for a given time step (Eq. 4), and the peak channel velocity is evaluated using Eq. 5:

$$
v_{c}=\frac{R_{c h}^{2 / 3} \cdot s l p_{c h}^{1 / 2}}{n}
$$

Where,

$v_{c}=$ Flow velocity $(\mathrm{m} / \mathrm{s})$

$R_{c h}=$ Hydraulic radius for a given depth of flow $(\mathrm{m})$;

$s l p_{c h}=$ Slope along the channel length $(\mathrm{m} / \mathrm{m})$. 


$$
v_{c h, p k}=\operatorname{prf} \cdot v_{c}
$$

Where,

$v_{c h, p k}=$ Peak channel velocity $(\mathrm{m} / \mathrm{s})$

prf $=$ Peak rate adjustment factor;

$v_{c}=$ Flow velocity $(\mathrm{m} / \mathrm{s})$.

For each reach segment, its sediment transport capacity is calculated using Eq. 6.

$$
\operatorname{conc}_{\text {sed }, c h, m x}=c_{s p} \cdot v_{c h, p k}^{\text {spexp }}
$$

Where,

conc $_{\text {sed,ch,mx }}=$ Maximum concentration of sediment that can be transported by the water (ton $/ \mathrm{m}^{3}$ or $\left.\mathrm{kg} / \mathrm{L}\right)$

$c_{s p} \quad=$ A coefficient defined by the user;

$v_{c h, p k}=$ Peak channel velocity $(\mathrm{m} / \mathrm{s})$;

spexp $\quad=$ An exponent defined by the user.

During channel routing, sediment transport is a function of deposition and degradation, and which one dominates is decided by the sediment transport capacity of the reach segment $\left(\right.$ conc $\left._{\text {sed,ch,mx }}\right)$ and the sediment concentration in the reach segment at the beginning of the time step $\left(\operatorname{conc}_{\mathrm{sed}, \mathrm{ch,i}}\right)$. If $\mathrm{conc}_{\mathrm{sed,ch,i}}>\mathrm{conc}_{\mathrm{sed,ch,mx}}$, deposition is the dominant process, while if $c o n c_{s e d, c h, i}<c o n c_{s e d, c h, m x}$, then degradation dominates. When deposition dominates, the net amount of sediment deposited is evaluated as (Eq. 7): 


$$
\operatorname{sed}_{d e p}=\left(\text { conc }_{\text {sed }, c h, i}-\operatorname{conc}_{\text {sed }, c h, m x}\right) \cdot V_{c h}
$$

Where,

$\operatorname{sed}_{d e p} \quad=$ Net amount of sediment deposited in the reach segment (metric tons);

conc $_{\text {sed,ch }, i}=$ Sediment concentration in the reach segment at the beginning of the time step (ton $/ \mathrm{m}^{3}$ or $\left.\mathrm{kg} / \mathrm{L}\right)$;

conc $_{\text {sed,ch, } m x}=$ Sediment transport capacity of the reach segment (ton $/ \mathrm{m}^{3}$ or $\mathrm{kg} / \mathrm{L}$ ), as defined in Eq. 6;

$V_{c h} \quad=$ Volume of water in the reach segment $\left(\mathrm{m}^{3} \mathrm{H}_{2} \mathrm{O}\right)$.

When degradation dominates, the net amount of sediment re-entrained is evaluated as (Eq. 8):

$$
\operatorname{sed}_{d e g}=\left(\operatorname{conc}_{\text {sed }, c h, m x}-\operatorname{conc}_{\text {sed }, c h, i}\right) \cdot V_{c h} \cdot K_{C H} \cdot C_{C H}
$$

Where,

$\operatorname{sed}_{d e g} \quad=$ Net amount of sediment re-entrained in the reach segment (metric tons);

conc $_{\text {sed,ch,mx }}=$ Sediment transport capacity of the reach segment (ton $/ \mathrm{m}^{3}$ or $\left.\mathrm{kg} / \mathrm{L}\right)$, as defined in Eq. 6;

$\operatorname{conc}_{\text {sed,ch,i}}=$ Sediment concentration in the reach segment at the beginning of the time step (ton $/ \mathrm{m}^{3}$ or $\left.\mathrm{kg} / \mathrm{L}\right)$;

$V_{c h} \quad=$ Volume of water in the reach segment $\left(\mathrm{m}^{3} \mathrm{H}_{2} \mathrm{O}\right)$;

$K_{C H}=$ Channel erodibility factor $(\mathrm{cm} / \mathrm{hr} / \mathrm{Pa})$;

$C_{C H} \quad=$ Channel cover factor. 


\subsubsection{SWAT Inputs and Procedure}

In this study, SWAT2005 was used to evaluate the performance of BMPs on a watershed level and ArcSWAT, which is an interface between SWAT and ArcGIS, was employed to prepare the SWAT inputs. The major input sources for SWAT are summarized in the Table 2.2. The input data is divided into GIS data and observed data. The GIS data includes the digital elevation model (DEM), soil map, and land use map. The observed data includes the weather and stream flow data. Since there is no weather station located in the study area, two stations with the shortest distance to the watershed were selected to provide the daily precipitation and temperature information (Figure 2.2). Weather information was attained from the closest station for each sub-watershed (WINCHELL et al. 2009). 
Table 2.2. SWAT inputs and sources

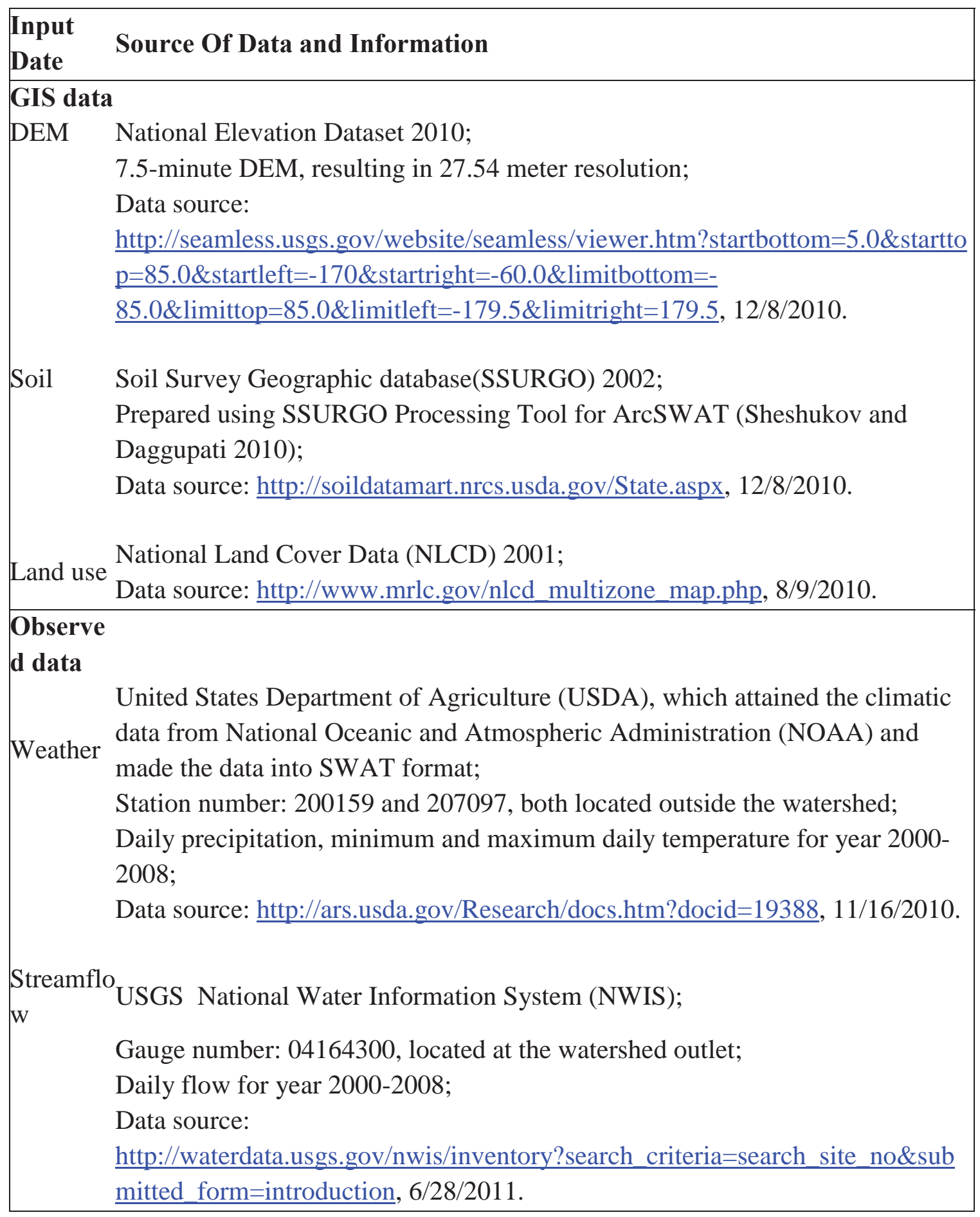




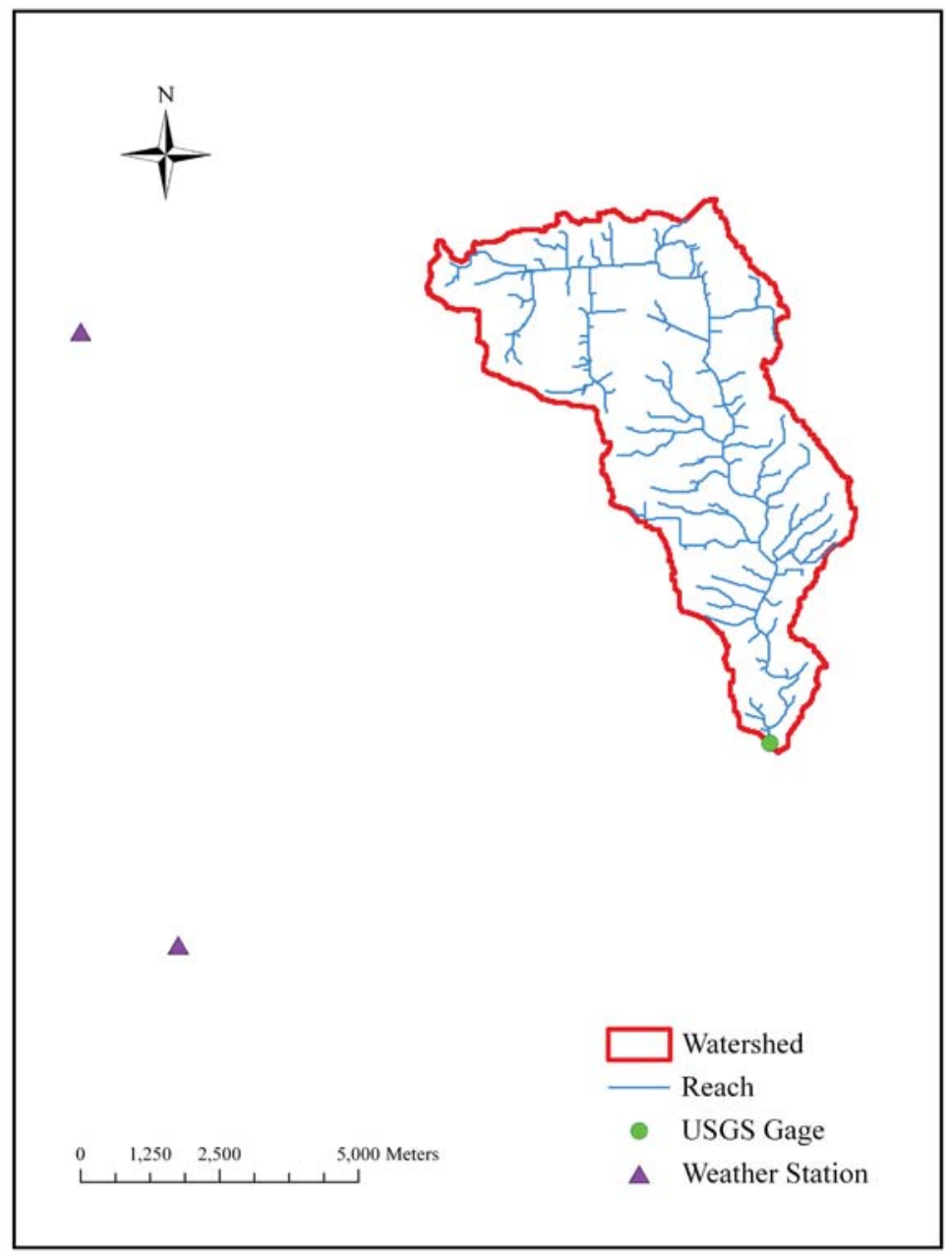

Figure 2.2. Locations for USGS gage and weather stations, figure by author using ArcSWAT.

The modeling procedure for the use of SWAT is shown in the Figure 2.3. The first step is to delineate the watershed into sub-watersheds based on the digital elevation model (DEM); the second step is to input the data for land use, soil type, and slope class; the third step is to divide each sub-watershed into different hydrologic response units (HRUs, defined as unique combinations of land use, soil, and management practice); the forth step is to input the weather information (daily precipitation, minimum and maximum daily temperatures). After estimating the hydrology, plant growth, management practice, 
and main channel routing in the study area, SWAT provides results of flow, sediment yield and water quality. After the calibration and validation of the model, this SWAT project is considered acceptable to evaluate the study area. The minimum sub-watershed area (critical source area) has been defined as small as possible to have more BMP location options, leading to 208 sub-watersheds and 208 main channel segments in the study area. Normally, an HRU may be comprised of scattered areas throughout a subwatershed, in order to know the specific location of the HRU and the corresponding BMP, in this study, each sub-watershed is defined as one HRU(Arabi et al. 2008, Kaini et al. 2008), which is characterized using the dominant land use, soil, and slope class in the sub-watershed (Figure 2.4).
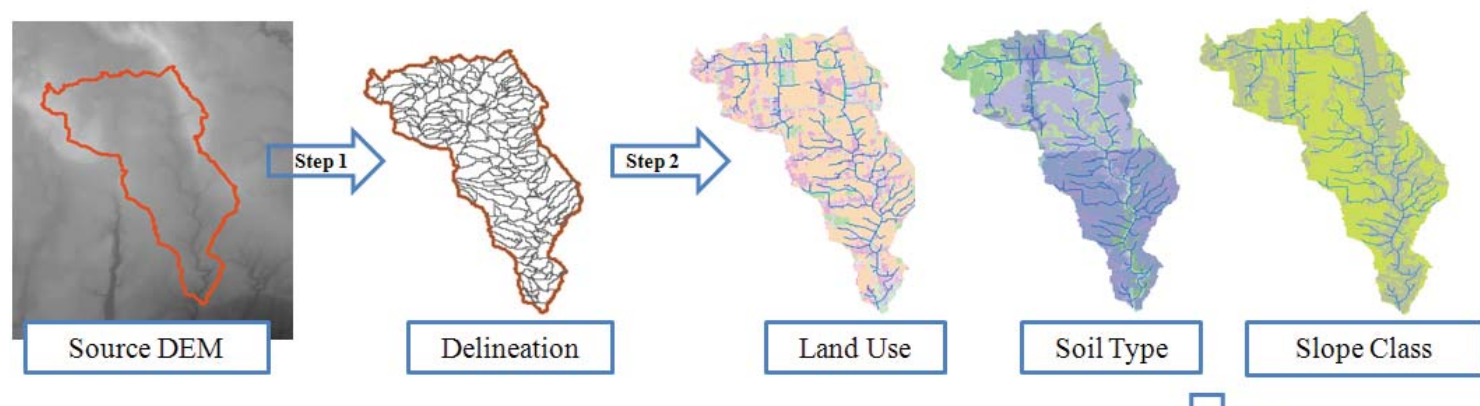

RESULTS:

Flow, Sediment, Water Quality

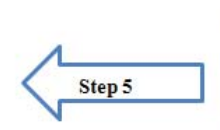

Hydrology, Land Cover/Plant Growth, Management Practice, Main Channel

Step 6 Routing, etc
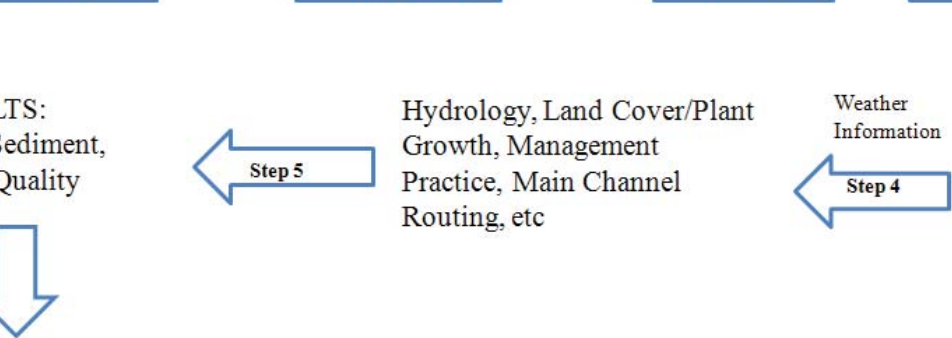

Calibration Validation
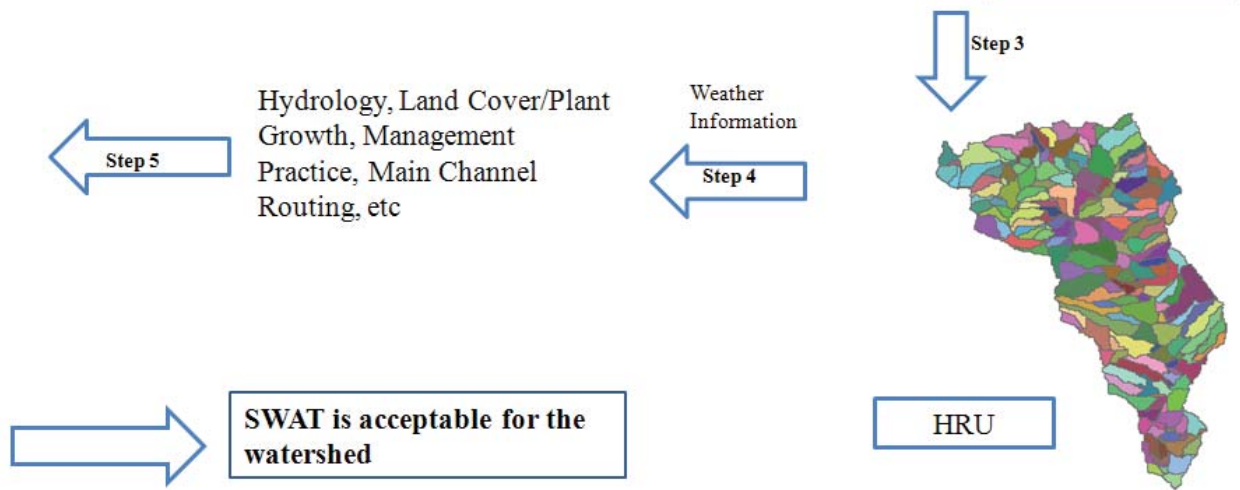

Figure 2.3. Modeling procedure of SWAT demonstrated on EB Coon Creek Watershed. 


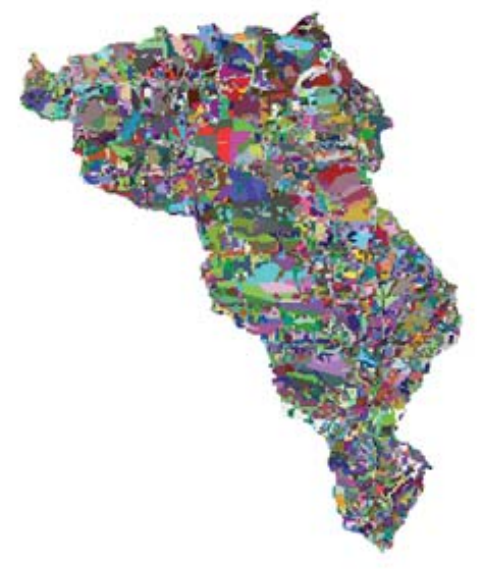

Full HRU
One sub-watershed was defined as one HRU.

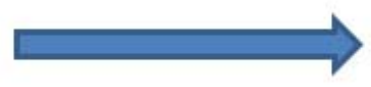

HRU

Figure 2.4. Before and after one sub-watershed was defined as one HRU.

\subsubsection{SWAT Calibration and Validation}

Before calibration, a sensitivity analysis was performed to decide the SWAT input parameters that were sensitive to the watershed outlet discharge (USGS gauge \# 04164300), using the "sensitivity analysis" function in ArcSWAT. The results (Table 2.3) of the sensitivity analysis helped select the most sensitive parameters for use in the calibration, hence saving calibration computation time. Since there was no available observed data for sediment, hence the sediment-related parameters were not involved in the sensitivity analysis. 
Table 2.3. Ranking of the sensitive SWAT input parameters for the watershed outlet discharge. The higher the ranking, the more sensitive the parameter.

\begin{tabular}{|l|ll|}
\hline Ranking & Flow Parameter & Meaning \\
\hline 1 & Alpha_Bf & Baseflow alpha factor, days \\
2 & Cn2 & Initial SCS CN II value \\
3 & Esco & Soil evaporation compensation factor \\
4 & Timp & Snow pack temperature lag factor \\
5 & Sol_Z & Soil depth, mm \\
6 & Sol_Awc & Available water capacity, $\mathrm{mm} \mathrm{H}_{2} \mathrm{O} / \mathrm{mm}$ soil \\
7 & Revapmn & Threshold water depth in shallow aquifer for "revap" \\
8 & Gwqmn & Threshold water depth in shallow aquifer for flow , mm \\
9 & Blai & Maximum potential leaf area index \\
10 & Canmx & Maximum canopy storage, mm \\
11 & Ch_K2 & Main Channel effective hydraulic conductivity, $\mathrm{mm} / \mathrm{hr}$ \\
12 & Biomix & Biological mixing efficiency \\
13 & Surlag & Surface runoff lag time, days \\
14 & Ch_N2 & Manning's "n" value for the main channel \\
15 & Epco & Plant uptake compensation factor \\
\hline
\end{tabular}

SWAT Calibration and Uncertainty Programs (SWAT-CUP) Version 2 (Abbaspour 2008) was employed for calibration and validation. Sequential Uncertainty Fitting 2 (SUFI2) (Abbaspour et al. 2007) was chosen as the calibration method since it achieves a similar level of accuracy with the smallest number of SWAT model runs, compared to other methods available in SWAT-CUP (Yang et al. 2008). Weather Data was available for the years 1950 to 2009 October. Data was used only from 2000 to 2008 to negate the effects of possible anthropogenic climate change. A warm-up period of 4 years was used to minimize the effect from the initial condition in SWAT such as a dry riverbed. Years 2004 to 2007 were employed for calibration while year 2008 was used for validation. Since no extreme storm or flooding happened within these five years (Figures 2.5 and 
2.6), the applicability of these results to extreme event periods is unclear. The effect of BMPs was evaluated for daily events which was the finest time scale of data available, to reduce the effects of time averaging. As a widely-used and highly recommended statistic (Moriasi et al. 2007), the Nash-Sutcliffe efficiency (N-S) (Nash and Sutcliffe 1970) was selected as the objective function for use in SUFI2. The coefficient of determination $\left(\mathrm{R}^{2}\right)$ was also calculated to test how robust the calibrated model was. The observed data used here was the daily flow at the watershed outlet (USGS gauge \# 04164300) for both calibration and validation. Seven SWAT parameters employed in the calibration (Table 2.4) were selected based on the sensitivity analysis (Table 2.3) and their value ranges for calibration were determined based on SWAT theoretical documentation (Neitsch et al. 2005). Since there was no available observed data for sediment, the channel cover factor and channel erodibility factor of Eq. 8 were both set to zero which corresponds to riverbed aggradation.

The N-S for calibration and validation were 0.6 and 0.59 (Table 2.5), respectively, both of which were larger than 0.5 , proving that the results were satisfactory (Moriasi et al. 2007). Also the $\mathrm{R}^{2}$ values were 0.63 and 0.74 for the calibration and validation, respectively. Typically, a value greater than 0.5 is acceptable for $\mathrm{R}^{2}$ (Moriasi et al. 2007), hence the $\mathrm{R}^{2}$ results supported that the SWAT calibration and validation were satisfactory. 
Table 2.4. SWAT parameters selected for calibration

\begin{tabular}{|crr|}
\hline Parameter & Calibration Range & $\begin{array}{r}\text { Calibrated } \\
\text { Value }\end{array}$ \\
\hline Alpha_Bf & {$[0,1]$} & 0.911 \\
Esco & {$[0.001,1]$} & 0.766 \\
Timp & {$[0.001,1]$} & 0.116 \\
Revapmn & {$[0,100]$} & 38.818 \\
Gwqmn & {$[0,3000]$} & 60.029 \\
Canmx & {$[0,10]$} & 3.524 \\
Ch_K2 & {$[0.001,150]$} & 91.839 \\
\hline
\end{tabular}

Table 2.5. Information and results for the SWAT calibration and validation, and value greater than 0.5 is acceptable (Moriasi et al. 2007)

\begin{tabular}{|c|c|c|c|c|}
\hline \multirow[b]{3}{*}{ Warm-up } & \multirow[b]{2}{*}{ period } & \multirow[b]{2}{*}{ year } & \multicolumn{2}{|c|}{ This Study } \\
\hline & & & N-S & $\mathbf{R}^{2}$ \\
\hline & $4 \mathrm{yrs}$ & $\begin{array}{l}2000-2003 \text { for calibration; } \\
2004-2007 \text { for validation. }\end{array}$ & & \\
\hline Calibration & $4 y r s$ & 2004-2007 & 0.60 & 0.63 \\
\hline Validation & $1 \mathrm{yrs}$ & 2008 & 0.59 & 0.74 \\
\hline
\end{tabular}




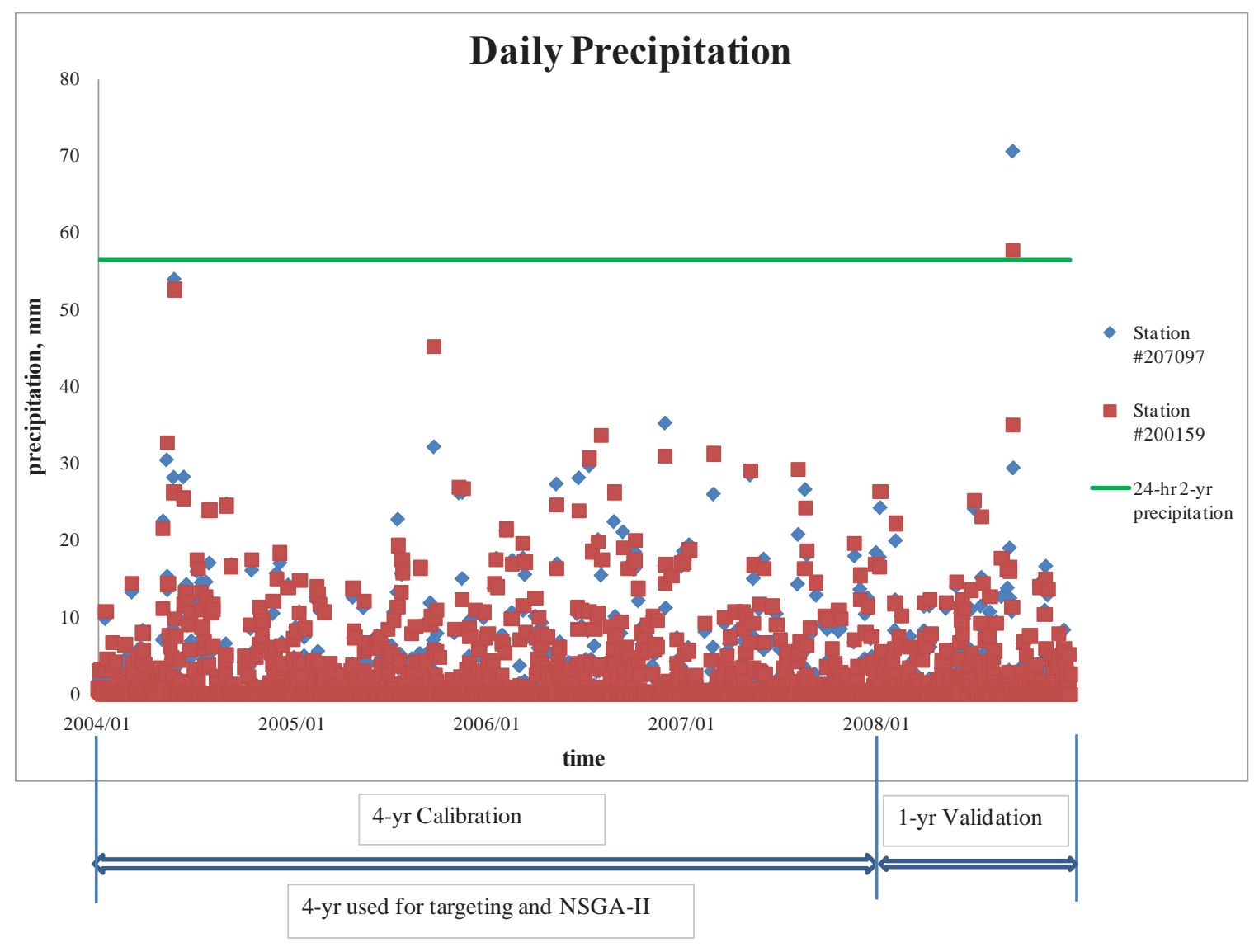

Figure 2.5. Daily precipitation for this study. 


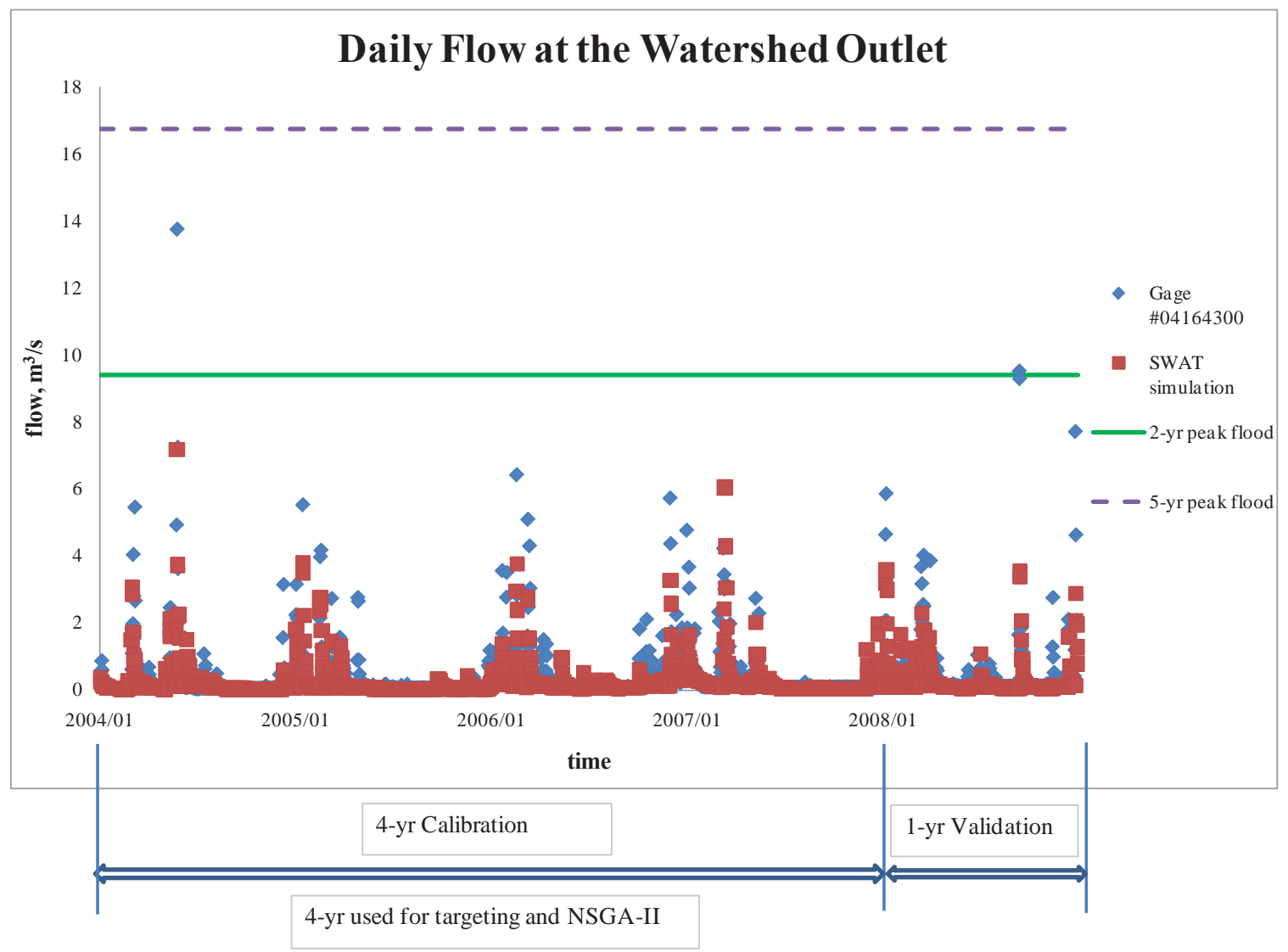

Figure 2.6. Daily flow at the watershed outlet for this study.

\subsection{BMPs Applied}

Best Management Practices (BMPs) are implementations designed to treat, prevent or reduce water pollution (DEQ 2011). There are many possible BMPs for use in agricultural watersheds. For simplicity and coverage of both land and waterways, the filter strip and grassed waterway were selected. A filter strip (Figure 2.7) is a strip of dense vegetation that removes sediment, organic material, nutrients, and chemicals carried in runoff through filtering and infiltration (DEQ 2011). A grassed waterway (Figure 2.8) is a vegetated channel that reduces the erosion and captures sediment and pollution (DEQ 2011). Both of these BMPs need proper maintenance to keep functional 
(DEQ 2011). For example, unwanted weeds and brush grown in the filter strips should be controlled. The grassed waterway needs to be mowed periodically to maintain dense sod.

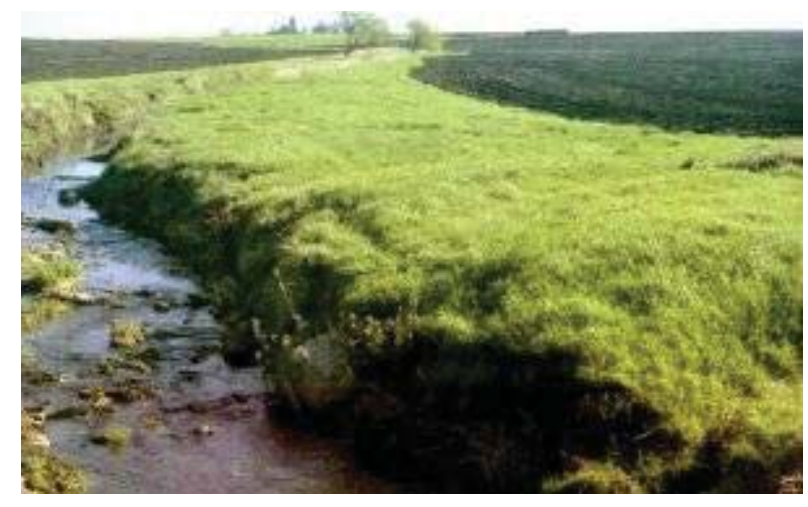

Figure 2.7. Filter Strip. Photo by EPA. http://web.epa.ohio.gov/dsw/nps/NPSMP/FUND/fundusda.html. 4/24/2011.

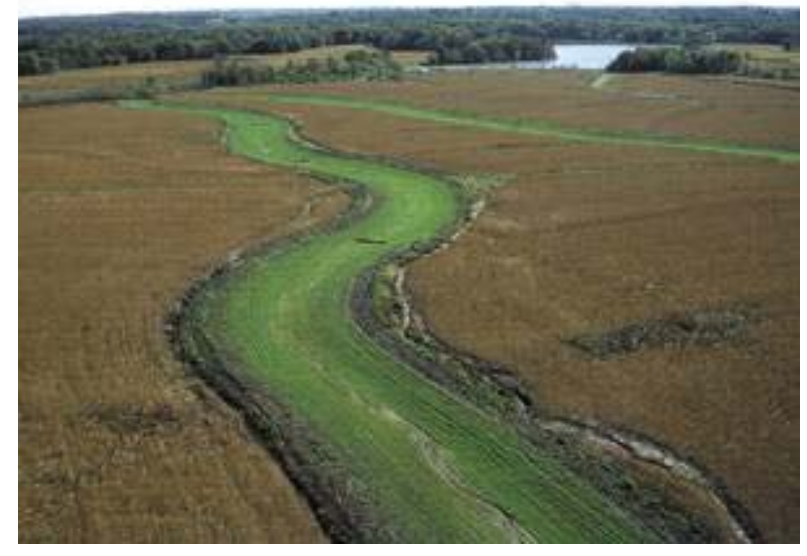

Figure 2.8. Grassed Waterway. Photo by Charlie Rahm, USDA Natural Resources Conservation Service.

http://www.ers.usda.gov/Amberwaves/September04/Features/measuringsuccess.htm. $4 / 24 / 2011$. 
In SWAT, the BMPs are represented using parameters. The SWAT parameters for the filter strip and grassed waterway are listed in Table 2.6. For the filter strip, the sediment trapping efficiency is decided by its width (Eq. 9).

$$
\operatorname{trap}_{\text {ef }}=0.367 \cdot\left(\text { width }_{\text {filstrip }}\right)^{0.2967}
$$

Where,

trap $_{e f} \quad=$ Fraction of the constituent loading trapped by the filter strip;

width $_{\text {filtstrip }}=$ Width of the filter strip (m).

For the grassed waterway, SWAT increases the trapping of sediment by reducing the channel flow velocity (Eq. 4 in Section 2.2.2), which leads to a decreased sediment transport capacity (Eq. 5 and Eq. 6 in Section 2.2.2). Also the grassed waterway reduces the gully erosion (Eq. 8 in Section 2.2.2) by establishing channel cover in the streambed/ banks (Arabi et al. 2008). 
Table 2.6. SWAT representations of filter strip and grassed waterway

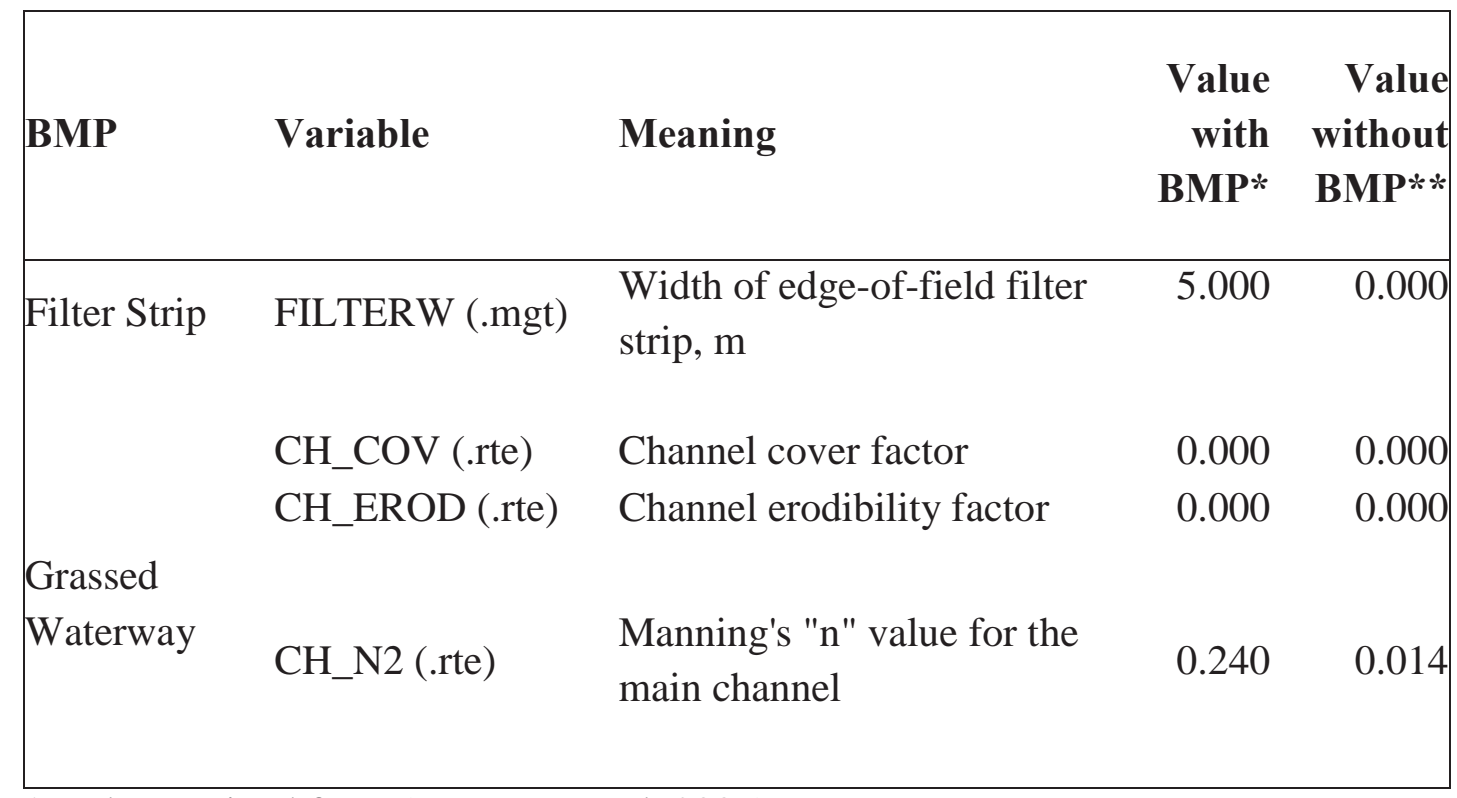

* Value attained from (Bracmort et al. 2006).

** Default value assigned by SWAT. 


\subsubsection{Total BMP Cost}

The BMP cost information is estimated using data collected by the United States Department of Agriculture (USDA) and Natural Resources and Conservation Service (NRCS) at levels of the county and state (Table 2.7). In this study, the total BMP cost is the sum of the Life Cycle Net Present Value of all the BMPs applied in the allocation (Eq. 10) and the Life Cycle Net Present Value of each individual BMP is calculated using Eq. 11 (USDA and NRCS, http://www.dnrec.state.de.us/water2000/Sections/Watershed/ws/IB_PCS_final_and_appe ndices.pdf, 4/15/2011).

Table 2.7. BMP Costs, attained from USDA and NRCS*

\begin{tabular}{|c|c|c|}
\hline BMP & Filter Strip & Grassed Waterway \\
\hline Installation Cost (\$/acre) & 300 & 2,500 \\
\hline Maintenance Cost (\$/acre/year) & 5 & 5 \\
\hline Land Rental (\$/acre/year) & 65 & 65 \\
\hline Life Time (yr) & 10 & 10 \\
\hline Interest Rate (\%) & $3 \%$ & $3 \%$ \\
\hline $\begin{array}{c}\text { Life Cycle Net Present Value Per } \\
\text { Acre (\$/acre) }\end{array}$ & 897.11 & 3097.11 \\
\hline
\end{tabular}

*USDA and NRCS

(http://www.dnrec.state.de.us/water2000/Sections/Watershed/ws/IB_PCS_final_ and_appendices.pdf, 4/15/2011). 


$$
\begin{gathered}
\text { Total BMPCost }=\sum C=\sum \text { Area }_{\text {BMP }} \cdot P_{\text {LiffCycle }} \\
P_{\text {LifeCycle }}=P_{\text {Install }}+P_{\text {Maintain }}+P_{\text {LandRental }} ; \\
P_{\text {Maintain }}=A_{\text {Maintain }}\left(P / A_{\text {Maintain }}, i \%, n\right)=A_{\text {Maintain }} \frac{(1+i)^{n}-1}{i(1+i)^{n}} ; \\
P_{\text {LandRental }}=A_{\text {LandRental }}\left(P / A_{\text {LandRental }}, i \%, n\right)=A_{\text {LandRental }} \frac{(1+i)^{n}-1}{i(1+i)^{n}} .
\end{gathered}
$$

Eq. 10

Where,

Total BMP Cost $=$ Total cost for a BMP allocation $(\$)$;

C $\quad=$ Life cycle net present value for a single BMP (\$);

Area $_{B M P}=$ Area of the BMP (acre);

$P_{\text {LifeCycle }} \quad=$ Life cycle net present value per acre $(\$ /$ acre $)$;

$P_{\text {Install }} \quad=$ Present Value of Installation Cost $(\$ /$ acre $) ;$

$P_{\text {Maintain }} \quad=$ Present Value of Life Cycle Maintenance Cost $(\$ /$ acre $) ;$

$P_{\text {LandRental }} \quad=$ Present Value of Life Cycle Land Rental (\$/acre);

$A_{\text {Maintain }}=$ Uniform amount for Maintenance per year (\$/acre/year);

$A_{\text {LandRental }}=$ Uniform amount for Land Rental per year (\$/acre/year);

$i \% \quad=$ Interest Rate $(\%) ;$

$n \quad \quad=$ Life Time $(\mathrm{yr})$. 


\section{Chapter 3. BMP Number and Placement Selection by}

\section{Targeting}

\subsection{Objectives}

The objective of this chapter is to determine the best targeting criteria for both on-land and in-stream BMPs. Later, the best criterion is applied to find the optimal number and placement of BMPs based on sediment yield reduction and total BMP cost.

\subsection{Introduction to Targeting}

Targeting in general is the ranking of solutions based on a solution of a single implementation of an alternative rather than attempt multiple-implementation solutions. In the case of BMP application on a watershed, each candidate of BMP location is ranked based on the sediment yield from either the sub-watershed or at the outlet of the entire watershed, following the order from most to least (potential) sediment yield reduction. The assumption is that applying BMPs to locations in this order will result in a nearoptimal way.

The first criterion, Criterion A, ranks each sub-watershed based on the sediment yield per hectare of the sub-watershed with no BMPs (filter strip for this study) installed, and this criterion was used in other studies (Parajuli et al. 2008, Tuppad et al. 2010). Criterion B is similar to Criterion A (still a sub-watershed and no filter strips), except that in Criterion B each sub-watershed is ranked based on total sediment yield from the whole subwatershed (not per hectare, as in Criterion A). The theory behind Criteria A and B is that 
placing a BMP on the sub-watershed with the most sediment yield will result in the largest reduction in sediment coming from the sub-watershed to the waterway, hence may lead to a huge decrease of the sediment yield at the watershed outlet.

Criterion $\mathrm{C}$ ranks each BMP location (sub-watersheds or main channel segments) based on the individual effect of the BMP (filter strips for sub-watersheds or grassed waterways for main channel segments) installed in that location to the entire watershed outlet sediment yield. The theory behind Criterion $\mathrm{C}$ is that a BMP allocation, constituted with the BMPs that have the biggest individual impacts to the watershed outlet sediment yield, may have a largest combined effect to the watershed outlet sediment yield.

For the on-land BMPs (e.g. filter strip), three criteria (Criterion A, B, and C) are investigated. For the in-stream BMPs (e.g. grassed waterway), only one criteria is applicable (Criterion C). Details about each criterion are listed in Table 3.1.

Years 2004-2007 were employed as simulation period for targeting, using years 20002003 as warm-up period. 
Table 3.1. Description of each targeting criterion

\begin{tabular}{|c|l|}
\hline Criterion* & \multicolumn{1}{|c|}{ Description $* *^{* *}$} \\
\hline A & $\begin{array}{l}\text { Using no BMP, each sub-watershed is ranked based on overland sediment } \\
\text { yield per hectare from that sub-watershed (ton/ha/yr). }\end{array}$ \\
\hline B & $\begin{array}{l}\text { Using no BMP, each sub-watershed is ranked based on total overland } \\
\text { sediment yield from that sub-watershed (ton/yr). }\end{array}$ \\
\hline C & $\begin{array}{l}\text { Each BMP location (sub-watersheds or main channel segments) is ranked } \\
\text { based on the sediment yield from the watershed outlet with a BMP on each } \\
\text { location, one at a time (ton/yr). }\end{array}$ \\
\hline
\end{tabular}

* Criterion A and B are only suitable for the on-land BMP (e.g. filter strips) which is installed on the sub-watershed, while Criterion C works for on-land BMP as well as instream BMP, the latter of which can be implemented in the main channel segments.

**Years 2000-2003 used as warm-up period to remove effects of initial conditions in SWAT. Simulation period was 2004-2007.

\subsection{Procedure of Targeting}

The targeting procedure contains two main steps (Figure 3.1): Criteria Comparison and Targeting Based on Cost. In Criteria Comparison, targeting results based on the three different criteria (A, B, and C) are compared, and the criterion leading to the best result is chosen for the Targeting Based on Cost-Effectiveness. The procedure of targeting has been coded by the author using MATLAB. 


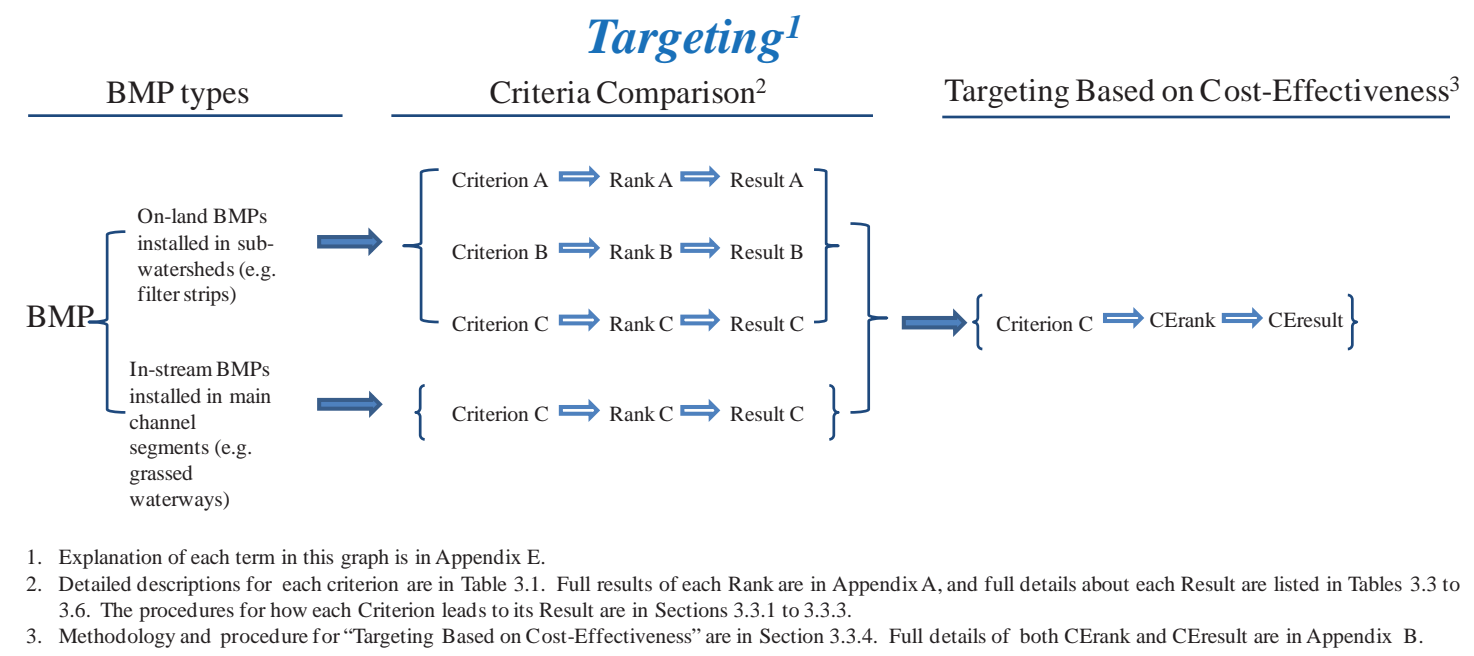

Figure 3.1. Outline of targeting

\subsubsection{Targeting Using Criterion A}

Criterion A is only suitable for the on-land BMPs (e.g. filter strip), the implantation locations of which are sub-watersheds. Targeting using Criterion A includes 3 basic steps:

Step 1: Calculate the 4-yr average sediment yield per hectare from each sub-watershed (SY sub_ha $)($ ton/ha/yr), one-by-one, with no BMPs placed;

Step 2: Rank each sub-watershed based on these values and the sub-watershed with a larger sediment yield value (i.e. a larger potential sediment yield reduction) is given a higher ranking. Name this rank as Rank A;

Step 3: Install BMPs according to the order of Rank A for different watershed BMP coverage. Name this result as Result A. 


\subsubsection{Targeting Using Criterion B}

Criterion B also is only suitable for on-land BMPs (e.g. filter strip), which are installed in sub-watersheds. Targeting using Criterion B includes 3 basic steps:

Step 1: Calculate the 4-yr average total sediment yield from each sub-watershed (SY $\left.\mathrm{Sub}_{\text {stotal }}\right)($ ton/yr), one-by-one, with no BMPs placed;

Step 2: Rank each sub-watershed based on these values and the sub-watershed with a larger sediment yield value (i.e. a larger potential sediment yield reduction) is given a higher ranking. Name this rank as Rank B;

Step 3: Install BMPs according to the order of Rank B for different watershed BMP coverage. Name this result as Result B.

\subsubsection{Targeting Using Criterion $\mathrm{C}$}

Criterion $\mathrm{C}$ is suitable for the on-land BMPs (e.g. filter strips) as well as the in-stream BMPs (e.g. grassed waterways). The locations for filter strips are sub-watersheds, and for the grassed waterways are main channel segments. Targeting using Criterion $\mathrm{C}$ includes 3 basic steps:

Step 1: Calculate the 4-yr average total sediment yield from the entire watershed ( $\left.\mathrm{SY}_{\mathrm{ws}}\right)$ (ton/yr) with a BMP on each location, one-by-one;

Step 2: Rank each location based on these values, and the location with a smaller value (i.e. a larger sediment yield reduction, not the potential sediment yield reduction as 
used in Criterion A and B, in both of which no BMP is installed during the "Step 1") has a higher ranking. Name this rank as Rank C;

Step 3: Install BMPs according to the order of Rank $\mathrm{C}$ for different watershed BMP coverage. Name this result as Result C.

\subsubsection{Targeting Based on Cost-Effectiveness}

Cost-effectiveness of the BMP is evaluated using the sediment yield reduction per cost, as shown in Eq. 12:

$$
Y=\frac{\Delta S Y}{C}
$$

Where

$Y \quad=$ Sediment yield reduction per cost;

$\Delta S Y=$ Sediment yield reduction when only one BMP located in the watershed;

$C=$ Life cycle net present value for the single BMP which leads to the $\Delta S Y$.

Any of the three criteria mentioned above can be used for this cost analysis and the $\triangle S Y$ in Eq. 12 has different meanings for different criteria applied (Table 3.2). 
Table 3.2. Meaning of $\triangle S Y$ for different criteria

\begin{tabular}{|c|c|c|}
\hline Criterion & $\Delta$ SY Meaning & Unit \\
\hline A & $\begin{array}{l}\text { reduction of overland sediment yield per } \\
\text { hectare from the sub-watershed compared to } \\
\text { baseline*, } \Delta \mathrm{SY}_{\text {sub_ha }}\end{array}$ & metric ton/ha/yr \\
\hline B & $\begin{array}{l}\text { reduction of overland sediment yield from the } \\
\text { whole sub-watershed compared to baseline*, } \\
\Delta \mathrm{SY}_{\text {sub_total }}\end{array}$ & metric ton/yr \\
\hline $\mathrm{C}$ & $\begin{array}{l}\text { reduction of watershed outlet sediment yield } \\
\text { compared to baseline*, } \Delta \mathrm{SY}_{\mathrm{ws}}\end{array}$ & metric ton/yr \\
\hline
\end{tabular}

*No BMPs located in the watershed.

The steps for targeting with the cost-effectiveness can be summarized in 3 steps:

Step 1: Calculate the 4-yr average sediment yield reduction per cost ( $Y$ in Eq. 12) with a BMP on each location, one-by-one;

Step 2: Rank each location based on these values, the location with a larger value has a higher ranking. Name this rank as CErank;

Step 3: Add BMPs according to the order of CErank, one BMP at a time, until all locations have a BMP installed. Name this result as CEresult. 


\subsection{Results of Targeting}

\subsubsection{Results of Targeting for the Filter Strip Application}

Rank A (Table A.1 in Appendix A for full details) shows that the overland sediment yield per hectare $\left(\mathrm{SY}_{\text {sub_ha }}\right.$ in ton/ha/yr) from different sub-watersheds ranges from 0 ton/ha/yr to 4.251 ton/ha/yr. Sub-watershed 95 is the only one with no sediment yield, most likely as a result of its land use of Deciduous Forest. Different $\mathrm{SY}_{\text {sub_ha }}$ values result from the effects of different combinations of land use, soil type, slope class, and management practices. Since some sub-watersheds have more $\mathrm{SY}_{\text {sub_ha }}$ than others, filter strips installed in these sub-watersheds may catch more overland sediment compared to that of filter strips in other sub-watersheds, therefore decreasing the amount of sediment from the land to the river.

When comparing Rank A and Rank B for filter strip application (Table A.2 in Appendix A), it is found that the same sub-watershed may have a different ranking for the various ranking criteria. For example, sub-watershed No.26 is ranked $11^{\text {th }}$ in Rank A, but $2^{\text {nd }}$ in Rank B. This implies that the total overland sediment yield (SY $\mathrm{Sub}_{\text {_total }}$ in ton/yr) from the sub-watershed is not only influenced by the different combinations of land use, soil type, slope class, and management practices but also by the total area of the sub-watershed.

Rank C for filter strips (Table A.3 in Appendix A) indicates that the 5-m filter strip installed in different sub-watersheds may lead to different watershed outlet sediment yields ( $\mathrm{SY}_{\mathrm{ws}}$ ) values, ranging from 200.1 ton/yr to 206.9 ton/yr. Also, comparing Rank C to Rank A and Rank B, the same sub-watersheds may have a different ranking under 
different criteria. For example, sub-watershed No.26 is ranked as $11^{\text {th }}, 2^{\text {nd }}$, and $27^{\text {th }}$ in Rank A, Rank B, and Rank C, respectively. This suggests that the filter strip installed in sub-watersheds with a high overland sediment yield cannot guarantee a higher reduction of watershed outlet sediment yield when compared to the filter strip in other subwatersheds with a less overland sediment yield.

After finding the rank based on different criteria ("Step 2" of Sections 3.3.1 to 3.3.3), filter strips were installed in sub-watersheds according to different ranks as described in "Step 3" of Sections 3.3.1 to 3.3.3. Result A, Result B, and Result C are based on Rank A, Rank B, and Rank C, respectively. Result A (Table 3.3) shows that when the watershed BMP coverage is from $5 \%$ to $25 \%$, the watershed outlet sediment yield reduction $\left(\Delta \mathrm{SY} \mathrm{ws}_{\mathrm{ws}}\right.$ ) is less than $5 \%$. When the watershed BMP coverage increases to $50 \%$, $\Delta \mathrm{SY}_{\mathrm{ws}}$ is around $15 \%$. Result B (Table 3.4) indicates that for a watershed BMP coverage with less than or equal to $10 \%, \Delta \mathrm{SY}_{\mathrm{ws}}$ is less than $5 \%$. When the watershed BMP coverage increases to $25 \%, \Delta \mathrm{SY}_{\mathrm{ws}}$ is higher than $10 \%$. In Result C (Table 3.5), for watershed BMP coverage of $5 \%, \Delta \mathrm{SY}_{\mathrm{ws}}$ is around $17 \%$. When the watershed BMP coverage is from $5 \%$ to $100 \%, \Delta \mathrm{SY}_{\mathrm{ws}}$ does not change much. 
Table 3.3. Result A for filter strips

\begin{tabular}{|rrrr|}
\hline $\begin{array}{l}\text { Watershed BMP } \\
\text { coverage * }\end{array}$ & $\begin{array}{r}\text { \# of sub- } \\
\text { watersheds with } \\
\text { 5-m filter-strip }\end{array}$ & $\begin{array}{r}\text { Watershed outlet } \\
\text { sediment yield, } \\
\text { metric tons/yr }\end{array}$ & $\begin{array}{r}\text { Reduction } \\
\text { compared to } \\
\text { baseline**, \% }\end{array}$ \\
\hline $0 \%$ & 0 & 206.9 & 0.000 \\
$5 \%$ & 10 & 200.0 & 3.335 \\
$10 \%$ & 21 & 199.8 & 3.432 \\
$25 \%$ & 52 & 198.9 & 3.867 \\
$50 \%$ & 104 & 175.6 & 15.128 \\
$100 \%$ & 208 & 166.4 & 19.575 \\
\hline
\end{tabular}

*Percents of total sub-watersheds with 5-m filter strips.

**No BMPs located in the watershed.

Table 3.4. Result B for filter strips

\begin{tabular}{|rrrr|}
\hline $\begin{array}{r}\text { Watershed BMP } \\
\text { coverage * }\end{array}$ & $\begin{array}{r}\text { \# of sub- } \\
\text { watersheds with } \\
\text { 5-m filter-strip }\end{array}$ & $\begin{array}{r}\text { Watershed outlet } \\
\text { sediment yield, } \\
\text { metric tons/yr }\end{array}$ & $\begin{array}{r}\text { Reduction } \\
\text { compared to } \\
\text { baseline**, \% }\end{array}$ \\
\hline $0 \%$ & 0 & 206.9 & 0.000 \\
$5 \%$ & 10 & 199.3 & 3.673 \\
$10 \%$ & 21 & 198.7 & 3.963 \\
$25 \%$ & 52 & 184.4 & 10.875 \\
$50 \%$ & 104 & 178.4 & 13.775 \\
$100 \%$ & 208 & 166.4 & 19.575 \\
\hline
\end{tabular}

*Percents of total sub-watersheds with 5-m filter strips.

**No BMPs located in the watershed.

Table 3.5. Result $C$ for filter strips

\begin{tabular}{|rrrr|}
\hline $\begin{array}{r}\text { Watershed BMP } \\
\text { coverage * }\end{array}$ & $\begin{array}{r}\text { \# of sub- } \\
\text { watersheds with } \\
\text { 5-m filter-strip }\end{array}$ & $\begin{array}{r}\text { Watershed outlet } \\
\text { sediment yield, } \\
\text { metric tons/yr }\end{array}$ & $\begin{array}{r}\text { Reduction } \\
\text { compared to } \\
\text { baseline**, \% }\end{array}$ \\
\hline $0 \%$ & 0 & 206.9 & 0.000 \\
$5 \%$ & 10 & 171.6 & 17.061 \\
$10 \%$ & 21 & 170.2 & 17.738 \\
$25 \%$ & 52 & 168.6 & 18.511 \\
$50 \%$ & 104 & 167.4 & 19.091 \\
$100 \%$ & 208 & 166.4 & 19.575 \\
\hline
\end{tabular}

*Percents of total sub-watersheds with 5-m filter strips.

**No BMPs located in the watershed. 
By comparing Result A, Result B, and Result C (Figure 3.2), it can be concluded that:

1) The 5-m filter strip installed in different combinations of sub-watersheds may have different impacts on the watershed outlet sediment yield $\left(\mathrm{SY}_{\mathrm{ws}}\right)$ for the various targeting criteria (A, B, and C) investigated. For example, with a 5\% installation rate (10 sub-watersheds chosen), the $\mathrm{SY} \mathrm{ws}_{\mathrm{ws}}$ reduction $\left(\Delta \mathrm{SY} \mathrm{ws}_{\mathrm{ws}}\right)$ ranges from $3.335 \%$ for Result A to $17.061 \%$ for Result C;

2) The location of the filter strips can be more important than the total number of filter strips. For instance, when the watershed BMP coverage is 5\% (10 subwatersheds with filter strips) for Result C, $\Delta \mathrm{SY}_{\mathrm{ws}}$ is $17.06 \%$, which is better than both Results A and B under the watershed BMP coverage of a relatively high value of $50 \%$ (104 sub-watersheds with filter strips);

3) Result $\mathrm{C}$ is the best among the three results, since it leads to the highest $\Delta \mathrm{SY} \mathrm{ws}_{\mathrm{ws}}$ for any watershed BMP coverage. Hence Criterion $\mathrm{C}$ is the best criteria for targeting filter strips placement under this study condition. 


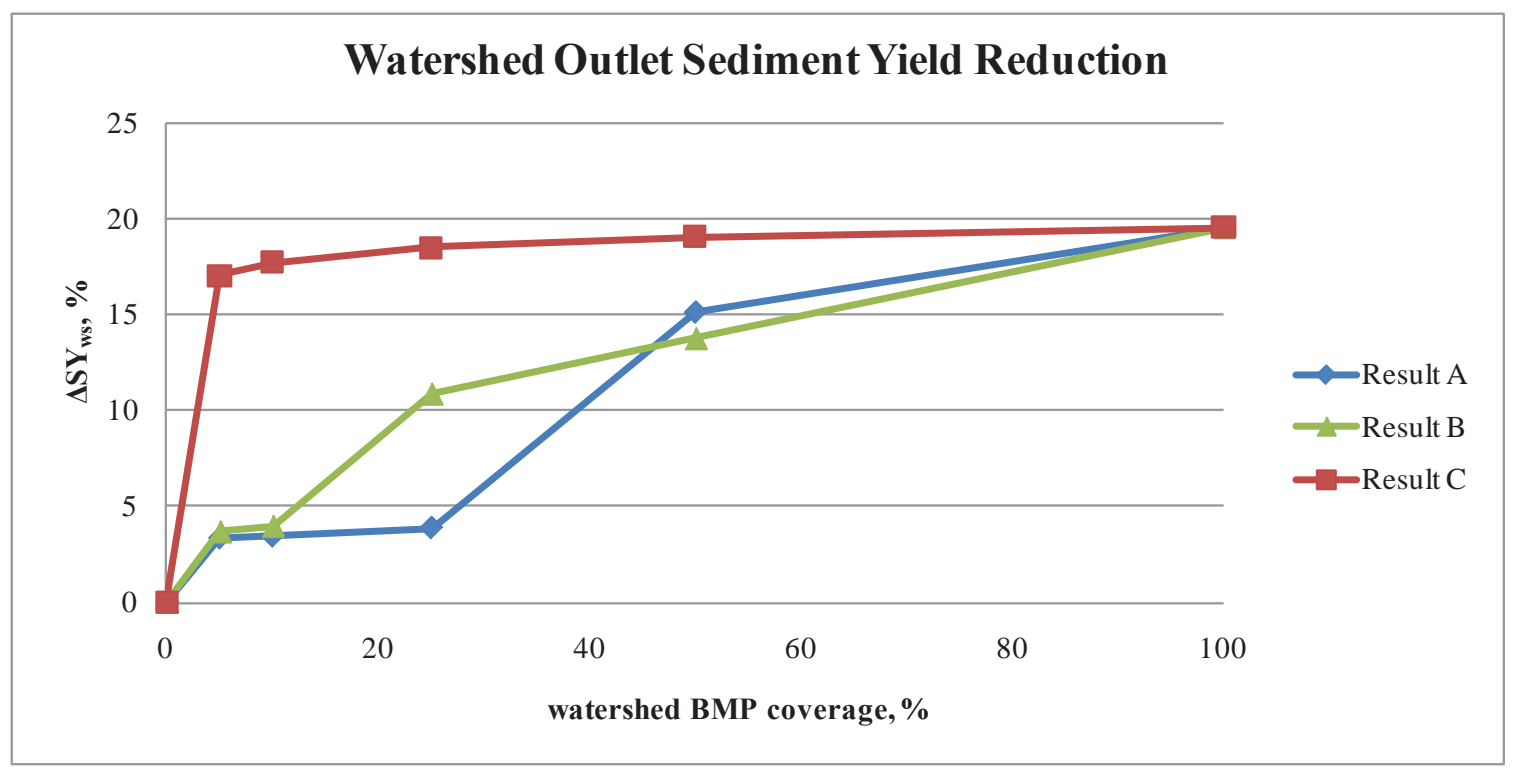

Figure 3.2. Effect of watershed BMP coverage on sediment yield for Results $A, B$, and $C$.

By comparing all the targeting criteria, Criterion $\mathrm{C}$ results in the highest sediment yield reduction (Figure 3.2). Result $\mathrm{C}$ tends to pick the sub-watersheds located near the watershed outlet (Figure 3.3), thereby having a large effect on the watershed outlet sediment yield if the main channel in the watershed is sediment deposition dominant.

Sediment deposition is the sediment in suspension that settles to the bottom of a liquid. By comparing the 4-yr average sediment transported with water into each reach (SEDIN) to the 4-yr average sediment transported with water out of each reach (SEDOUT), 94 out of 208 main channel segments have larger SEDIN than SEDOUT (Table A.5 in Appendix A), indicating that almost half of the main channel segments can be considered as sediment deposition-dominant during the 4-yr simulation period. As shown in Figure 3.4, those 94 channels are trunk channel segments, through which the sediment from the upstream water shed reaches has to pass to arrive at the watershed outlet. Since these trunk channel segments are sediment deposition-dominant, the sediment passing through 
them will have a high chance of depositing before it reaches the watershed outlet. In this watershed, the sediment from the upper sub-watershed has a higher chance of depositing before it reaches the watershed outlet, compared to the sediment from the lower subwatershed, since it has a further distance to travel and have more trunk channels, which are sediment deposition-dominant, to pass through. Hence, the sediment control (e.g. filter strips) installed near the watershed outlet has a higher impact on the watershed outlet sediment yield under this study condition.

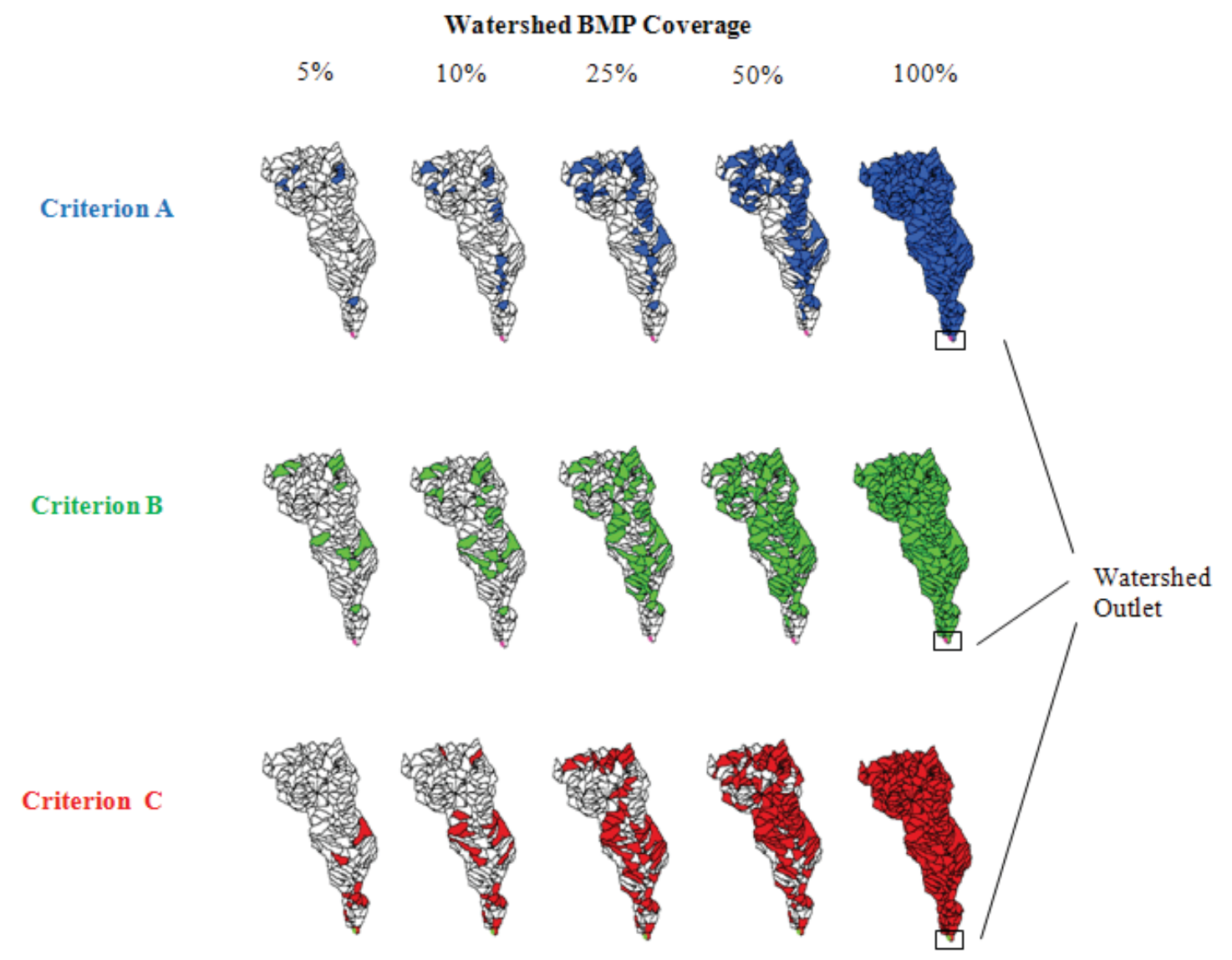

Figure 3.3. Sub-watersheds for filter strip placement, chosen based on different criteria. 


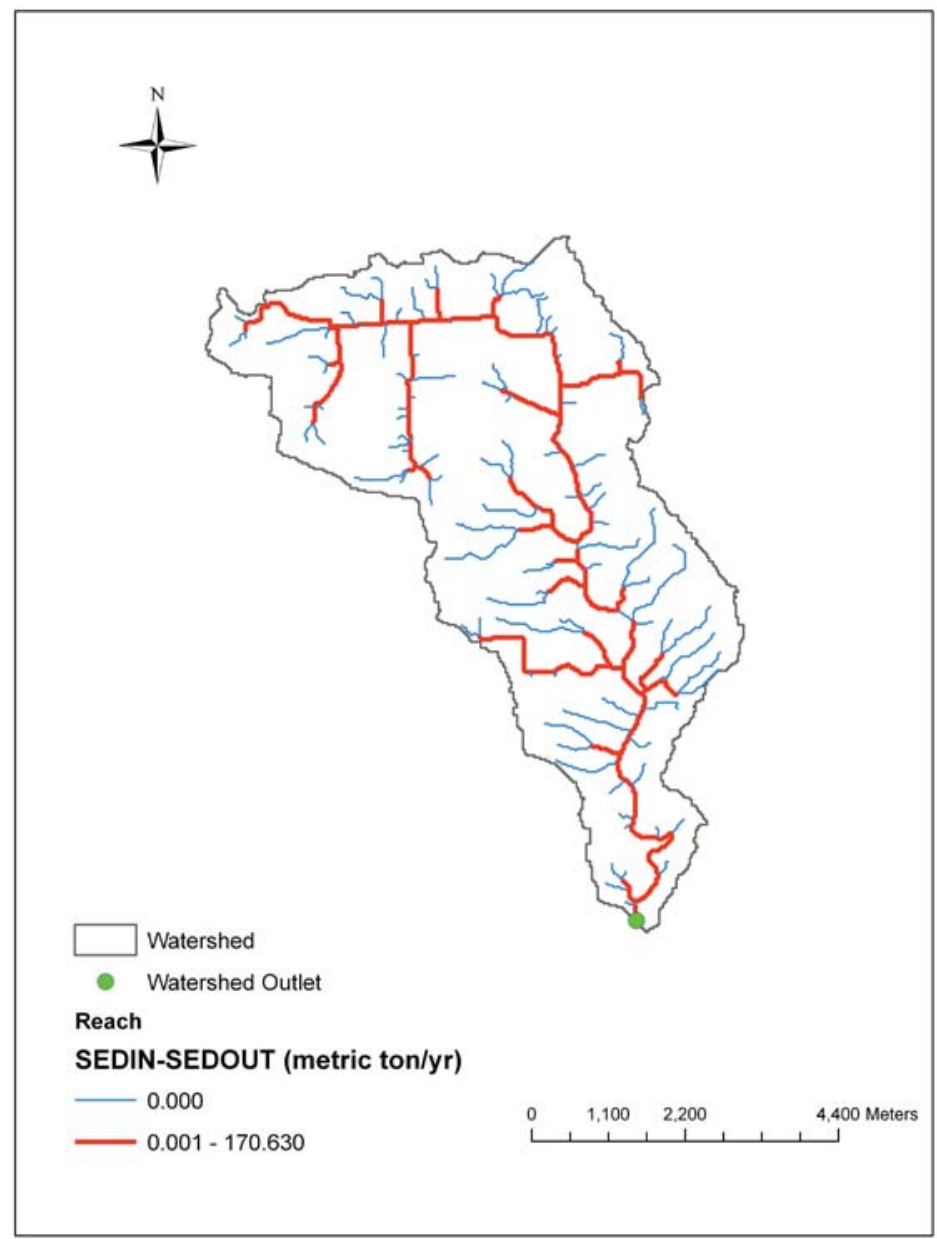

Figure 3.4. Location of main channel segments that are sediment deposition-dominant.

\subsubsection{Results of Targeting for the Grassed Waterway Application}

Only Criterion C applies to the in-stream BMP (e.g. grassed waterways). Rank C based on Criterion $\mathrm{C}$ for the grassed waterway is shown in Table A.4 of Appendix A and Result $\mathrm{C}$, the targeting result based on Rank C (procedure according to the "Step 3" of Section 3.3.3), is showed below in Table 3.6. Result C (Table 3.6) for grassed waterways shows that regardless of the watershed BMP coverage, the watershed outlet sediment reduction $\left(\Delta \mathrm{SY}_{\mathrm{ws}}\right)$ is always higher than that gained by the filter strip with the same watershed 
BMP coverage (Table 3.5). Based on this comparison, grassed waterways appear to be more effective than filter strips in reducing the watershed outlet sediment yield.

Table 3.6. Result $C$ for grassed waterways

\begin{tabular}{|rrrr|}
\hline $\begin{array}{r}\text { watershed BMP } \\
\text { coverage * }\end{array}$ & $\begin{array}{r}\text { \# of channel } \\
\text { segments with } \\
\text { grassed waterway }\end{array}$ & $\begin{array}{r}\text { watershed outlet } \\
\text { sediment yield, } \\
\text { metric tons/yr }\end{array}$ & $\begin{array}{r}\text { reduction } \\
\text { compared to } \\
\text { baseline**, \% }\end{array}$ \\
\hline $0 \%$ & 0 & 206.90 & 0.000 \\
$5 \%$ & 10 & 19.94 & 90.362 \\
$10 \%$ & 21 & 16.10 & 92.218 \\
$25 \%$ & 52 & 14.05 & 93.209 \\
$50 \%$ & 104 & 13.38 & 93.533 \\
$100 \%$ & 208 & 13.16 & 93.639 \\
\hline
\end{tabular}

*Percents of total main channel segments with grassed waterways.

**No BMPs located in the watershed.

Figure 3.5 below shows the main channel segment locations chosen by Criterion $\mathrm{C}$ for different watershed BMP coverage. Criterion $\mathrm{C}$ tends to pick the grassed waterways located near the watershed outlet, which trap the sediment from the whole watershed while those installed in other place only trap the sediment from upstream portions.

Based on the discussion above, grassed waterways located near the watershed outlet seem to be most effective in reducing the watershed outlet sediment yield under this study condition. 


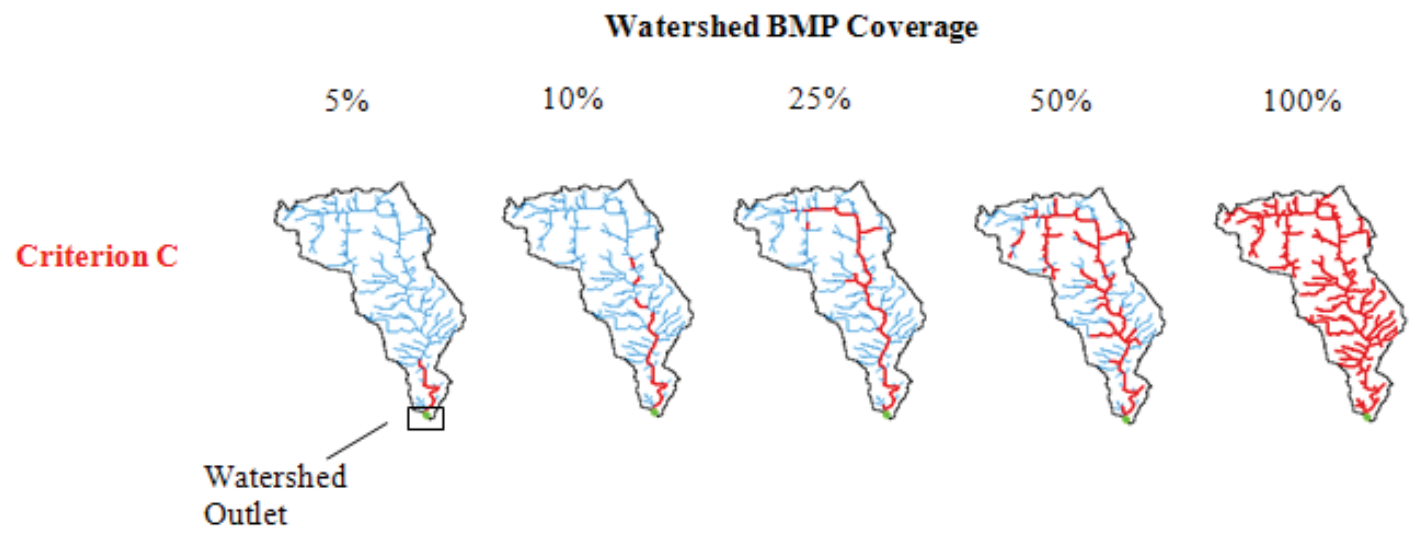

Figure 3.5. Main channel segments for grassed waterway placement, chosen based on Criterion $C$

\subsubsection{Results of Targeting Based on Cost-Effectiveness}

After applying the targeting method to the filter strip and grassed waterway individually, using different criteria, Criterion $\mathrm{C}$ was proven to be a good targeting method for both the on-land and in-stream BMPs. Hence Criterion C was chosen for targeting based on costeffectiveness (Eq. 12), following the procedure described in Section 3.3.4. There are 416 possible BMP locations: 208 sub-watersheds for filter strips and 208 main channel segments for grassed waterways.

The rank based on cost effectiveness (CErank) for both filter strips and grassed waterways (Table B.1 in Appendix B) shows that, even though the Life Cycle Net Present Value Per Acre (Table 2.7) for the grassed waterway (3,097.11 \$/acre) is more than 3 times that of the filter strip (897.11\$/acre), most of the BMPs with top rankings in the CErank are grassed waterways, since the grassed waterway is more effective in reducing the watershed outlet sediment yield $\left(\mathrm{SY}_{\mathrm{ws}}\right)$ as concluded in Section 3.4.2. 
After deciding the CErank, the CEresult (the targeting result based on cost-effectiveness) was attained according to "Step 3" in Section 3.3.4. CEresult (Table B.2 in Appendix B and Figure 3.6) shows that when the $S Y_{w s}$ falls between 104.6 and 16.62 ton/yr, the total cost of the BMPs ranges from $\$ 954$ to $\$ 49,427$. After that, when $S Y_{w s}$ decreases, the total cost increases dramatically, almost having a vertical gradient with little $\mathrm{SY}_{\mathrm{ws}}$ variation. The BMPs ranked at the bottom of the CErank, such as those yielding no sediment yield reduction per cost ( $Y$, as calculated in Eq. 12), will greatly reduce the overall BMP cost-effectiveness when they are added to the BMPs with a higher ranking, hence the more the BMPs are combined, the less the overall cost-effectiveness. This is evidenced by Figure 3.6: the higher the total BMP cost (more BMPs), the less the $\mathrm{SY}_{\mathrm{ws}}$ variation, leading to a steeper slope which indicates the added BMP is less cost-effective. 


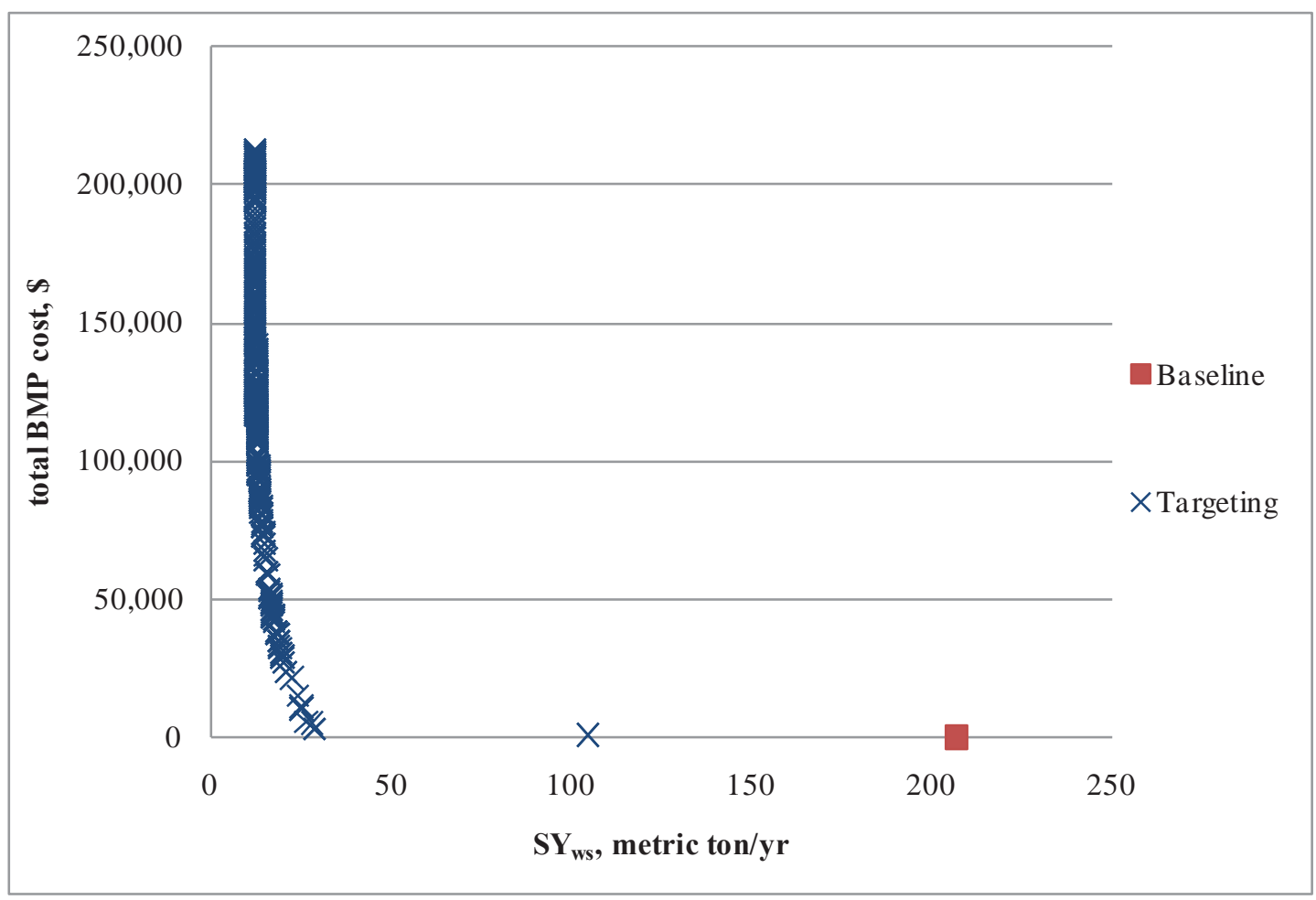

Figure 3.6. The targeting result based on cost-effectiveness. BMPs selected are 5-m filter strips and grassed waterways.

As shown in Tables B.1 and B.2 in Appendix B, the combined effect of the BMP allocation is not simply the sum of the individual effects of all the BMPs, and actually $\Delta \mathrm{SY}_{\mathrm{ws}}$ (reduction of $\mathrm{SY}_{\mathrm{ws}}$ compared to baseline) of the former is always smaller than that of the latter. This is due to the fact that the effect of a BMP changes under different circumstances, including the existence of other BMPs. For instance, the grassed waterway reduces erosion and increases sediment trapping. If other BMPs have been installed upstream of the grassed waterway, they may reduce the sediment coming to the grassed waterway so much that the grassed waterway traps no sediment (i.e. it is not "functional"), even though it traps a large amount of sediment if it was the only BMP installed in the watershed. Also, things can be explained the other way around: an 
existing BMP is affected by other newly added upstream BMPs. Hence, it is shown clearly in the CEresult (Table B.2 in Appendix B) that, sometimes, even though the BMP allocation has one more BMP (or even few more BMPs) than the previous allocation, it

yields the same amount of $\mathrm{SY}$ ws as the previous allocation does. Examples are the $3^{\text {rd }}, 4^{\text {th }}$, and $5^{\text {th }}$ allocations, which contain 3 BMPs, 4 BMPs, and 5 BMPs, respectively, but do not alter the sediment yield, $\mathrm{SY}_{\mathrm{ws}}$.

\subsection{Conclusions of Targeting}

There are three targeting criteria (A, B, and C) for the on-land BMP (e.g. filter strips) and one (Criterion C) for the in-stream BMP (e.g. grassed waterways) considered here. Comparing the results of different criteria, Criterion $\mathrm{C}$ has been proven to be the best option for the on-land BMP. This is because it tends to select the downstream subwatersheds which have a high effect on the watershed outlet sediment yield if the watershed main channel segments are sediment deposition-dominant. By comparing the placements of filter strips and grassed waterways selected by Criterion $\mathrm{C}$, it is found that grassed waterways near the watershed outlet reduced the watershed outlet sediment yield the most. Targeting based on cost-effectiveness has been applied to optimize the number and placement of both filter strips (on-land BMP) and grassed waterways (in-stream BMP) using Criterion $\mathrm{C}$ and resulted in the near-optimal allocation for both BMPs. 


\section{Chapter 4. BMP Number and Placement}

\section{Optimization by a Genetic Algorithm}

\subsection{Objectives}

The objective of Chapter 4 is to study the problem with two conflicting objective functions: minimizing the sediment yield and also cost. Optimizing the allocation of BMPs (both filter strips and grassed waterways) on a watershed level by combining a multi-objective optimization algorithm and SWAT is performed. This chapter provides a pseudo Pareto front, consisting of a group of pseudo Pareto optimization results of BMP allocations, which are the trade-offs between the total BMP cost and the watershed outlet sediment yield.

\subsection{Introduction to Optimization}

Multi-objective evolutionary algorithm (MOEA) is among the most popular of the multi-objective optimization algorithms, since it deals with discontinuous and concave Pareto fronts easily (Coello Coello 2006). Among MOEAs, the Non-dominated Sorting Genetic Algorithm II (NSGA-II) has been proven to be a better algorithm when compared to other kinds of MOEA (Deb et al. 2002).

\subsubsection{Non-dominated Sorting Genetic Algorithm II}

The Non-dominated Sorting Genetic Algorithm II (NSGA-II) adds to a simple Genetic Algorithm (GA) with sorting the solution based on the non-domination and crowding 
distance. A simple GA involves 5 basic steps (Fig 4.3): Fitness Evaluation, Natural Selection, Pairing, Crossover, and Mutation (Haupt and Haupt 1998). For the NSGAII, Fitness Evaluation contains a Non-Dominated Sorting Approach and Crowding Distance and Natural Selection involves a Crowded Comparison Operator (Deb et al. 2002).

In GA, a solution is called a chromosome, which is made of discrete units called genes. A collection of chromosomes is called the population, which is normally randomly initialized. GA applies Crossover and Mutation to generate new solutions from existing ones (Konak et al. 2006). In Crossover, two chromosomes (parents) are combined by exchanging a random portion with each other to generate two new chromosomes (offspring) (Figure 4.1). The parents are chosen from the mating pool during the Pairing (Haupt and Haupt 1998). In the mating pool, preference is given to the chromosomes with better fitness (e.g. the non-domination used by NSGA-II, as described below) for the objective functions, thereby, giving them higher rankings. The higher the rank of the chromosome in the mating pool, the higher the chance it will be selected to be the parent. By selecting the parents with better fitness, offspring are expected to inherit good genes which provide good fitness. After Crossover, Mutation is performed by altering a small percentage of the genes in the chromosomes. In a binary GA, when Mutation occurs, the value of the genes chosen is changed from 0 to 1 or from 1 to 0 (Figure 4.2). 

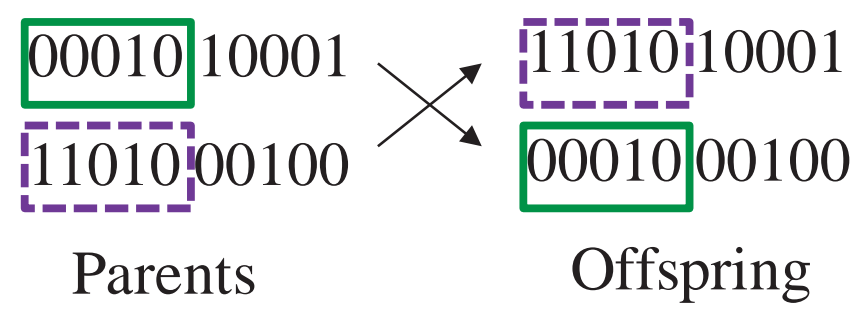

Figure 4.1. Crossover in a binary $G A$.

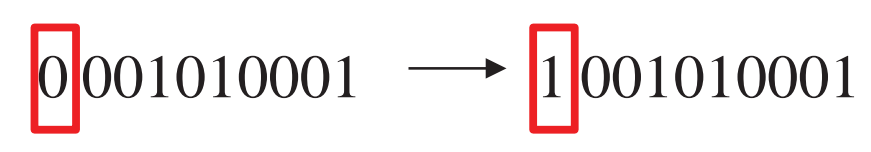

Figure 4.2. Mutation in a binary $G A$.

If all the objective functions are to be minimized, a feasible solution $x$ is said to dominate another feasible solution $y$, only if the following two conditions are both satisfied (Konak et al. 2006):

1) $\quad z_{i}(x) \leq z_{i}(y)$ for all objective functions \&

2) $\quad z_{i}(x)<z_{i}(y)$ for at least one objective function.

Where

$z=$ Objective function, $i=1,2 \ldots$

$x=$ The dominating solution;

$y=$ The dominated solution. 
If a solution is not dominated by any other solutions (i.e. it fits the objective functions best), this solution is said to be Pareto optimal. A Pareto optimal solution cannot gain improvement in any objective without worsening at least one other objective. All feasible non-dominated solutions constitute the Pareto optimal set, the corresponding objective function values namely the Pareto front. For many problems, it is practically impossible to indentify the entire Pareto optimal set, and also to prove the solution optimality due to the computational infeasibility. Hence, a realistic approach to multi-objective optimization is to find a set of solutions (the pseudo Pareto Front) to represent the Pareto front as much as possible. (Konak et al. 2006).

In the Non-Dominated Sorting Approach of Fitness Evaluation (Figure 4.3), each solution is sorted based on its non-domination. The solution, which is non-dominated by any other solutions, belongs to the best non-dominated front ( $F_{1}$, the Pareto front). The solution belonging to $F_{i}(\mathrm{i}>1)$ is dominated by other solutions from $F_{1}$ to $F_{i-1}$. Once the Non-Dominated Sorting Approach is finished, solutions in each nondominated front are sorted in ascending order based on each objective function during the calculation for crowding distance, which is to ensure the solutions selected by each generation are spatially well spread along the Pareto front and are far apart from each other in the solution space. If the attainable boundary values of each objective functions are known, the crowding distance is assigned using the known bound normalization, as shown in Eq. 13: 


$$
\begin{aligned}
& c d(x)=\sum_{k} c d_{k} ; \\
& \text { for } \mathrm{i}=1 \text { and } \mathrm{L} \\
& c d_{k}\left(x_{[i, k]}\right)=\infty \\
& \text { for } \mathrm{i}=2: \mathrm{L}-1 \\
& c d_{k}\left(x_{[i, k]}\right)=\frac{z_{k}\left(x_{[i+1, k]}\right)-z_{k}\left(x_{[i-1, k]}\right)}{z_{k}^{\max }-z_{k}^{\min }}
\end{aligned}
$$

Eq. 13

where

$c d=$ Crowding distance;

$x_{i} \quad=$ A solution $\mathrm{i}$ in the current front, $\mathrm{i}=1: \mathrm{L}$;

$k \quad=$ Objective function;

$z \quad=$ Objective function value;

$z_{k}^{\max }=$ The maximum obtainable value of the objective function $\mathrm{k}$;

$z_{k}^{\text {min }}=$ The minimum obtainable value of the objective function $\mathrm{k}$.

The $\frac{1}{z_{k}^{\max }-z_{k}^{\min }}$ in Eq. 13 is used to normalize the crowding distance so that it is not dominated by the objective function with a larger value. If the crowding distance is applied without proper normalization, it would lead to the biased distribution of solutions in the Pareto front (Pedersen and Goldberg 2004). The Crowded Comparison Operator (Figure 4.3) serves as a guide for the mating pool selection in that: for two solutions from different non-dominated fronts, $F_{i}$ and $F_{j}(\mathrm{i}<\mathrm{j})$ respectively, the one from $F_{i}$ is selected; for two solutions belonging to the same front, 
the one with the larger crowding distance is preferred.

\subsection{Procedure of Optimization}

The procedure of NSGA-II has been coded by the author using MATLAB. In the NSGA-II used by this study, each BMP allocation solution is defined as a binary 416gene chromosome, and each gene represents one possible BMP location: the first 208 genes represent 208 sub-watersheds as filter strip location candidates, and other genes stand for 208 main channel segments for possible grassed implementations. A gene value of 1 means a BMP installed, while 0 shows no BMP in this location. For example, if the $7^{\text {th }}$ and $209^{\text {th }}$ genes of the chromosome are 1 and 0 , respectively, it means that the $7^{\text {th }}$ sub-watershed has the filter strip implemented while the $1^{\text {th }}$ main channel segment does not have a grassed waterway.

Details about the GA parameters are listed in Table 4.1. In the Fitness Evaluation (Figure 4.3), the NSGA-II will call SWAT to evaluate the watershed outlet sediment yield $\left(\mathrm{SY}_{\mathrm{ws}}\right)$ based on the BMP allocation, after which the BMP cost is calculated. The $\mathrm{SY}_{\mathrm{ws}}$ for different BMP allocations is stored in a database, from which values are extracted, if available, thereby negating the need for SWAT for subsequent realizations and hence saving computational time. Years 2004-2007 were applied as the simulation period for NSGA-II, while years 2000-2003 were used as warm-up period to negate the effect of initial conditions in SWAT. 
The objectives of the NSGA-II applied here are:

1) Minimize the watershed outlet sediment yield $\left(\mathrm{SY}_{\mathrm{ws}}\right)$;

2) Minimize total BMP cost.

Based on the NSGA-II objectives of this study and the theory of domination in NSGA-II, solution $x$ is said to dominate another feasible solution $y$, if either of these situation happens:

Situation 1:

1) total BMP $\operatorname{cost}(\boldsymbol{x}) \leq$ total BMP $\operatorname{cost}(\boldsymbol{y}) \&$

2) $\mathrm{SY}_{\mathrm{ws}}(\boldsymbol{x})<\mathrm{SY}_{\mathrm{ws}}(\boldsymbol{y})$.

Situation 2:

1) total BMP $\operatorname{cost}(\boldsymbol{x})<$ total BMP $\operatorname{cost}(\boldsymbol{y}) \&$

2) $\mathrm{SY}_{\mathrm{ws}}(\boldsymbol{x}) \leq \mathrm{SY}_{\mathrm{ws}}(\boldsymbol{y})$.

$x=$ The dominating solution;

$y=$ The dominated solution. 
Table 4.1. Details of the GA parameters

\begin{tabular}{|c|c|c|}
\hline GA Parameter & Value & Description \\
\hline Total generation & 150 & $\begin{array}{l}\text { With } 1 \text { initial generation (gen=0) and } 150 \text { generations } \\
\text { (gen=1 150) (Srivastava et al. 2002). }\end{array}$ \\
\hline Population_ini & 80 & Population for the initial generation (gen=0). \\
\hline Population & 40 & Population for gen $=1 \sim 150$. \\
\hline Genes & 416 & $\begin{array}{l}\text { Genes for each chromosome, } \\
\text { representing } 208 \text { sub-watersheds and } 208 \text { main channel } \\
\text { segments. }\end{array}$ \\
\hline Mutation rate & 0.01 & $\begin{array}{l}\text { Number of genes to mutate }=\text { mutate rate*population*genes } \\
=166.4 \text {, which is rounded to } 167=\text { number of genes to be } \\
\text { selected randomly to mutate (from } 0 \text { to } 1 \text { or from } 1 \text { to } 0 \text { ) } \\
\text { except in the last generation (gen }=150 \text { ) (Haupt and Haupt } \\
\text { 1998). }\end{array}$ \\
\hline Keepgood & $50 \%$ & $\begin{array}{l}\text { Percent of chromosomes kept for mating pool during the } \\
\text { natural selection process. }\end{array}$ \\
\hline
\end{tabular}




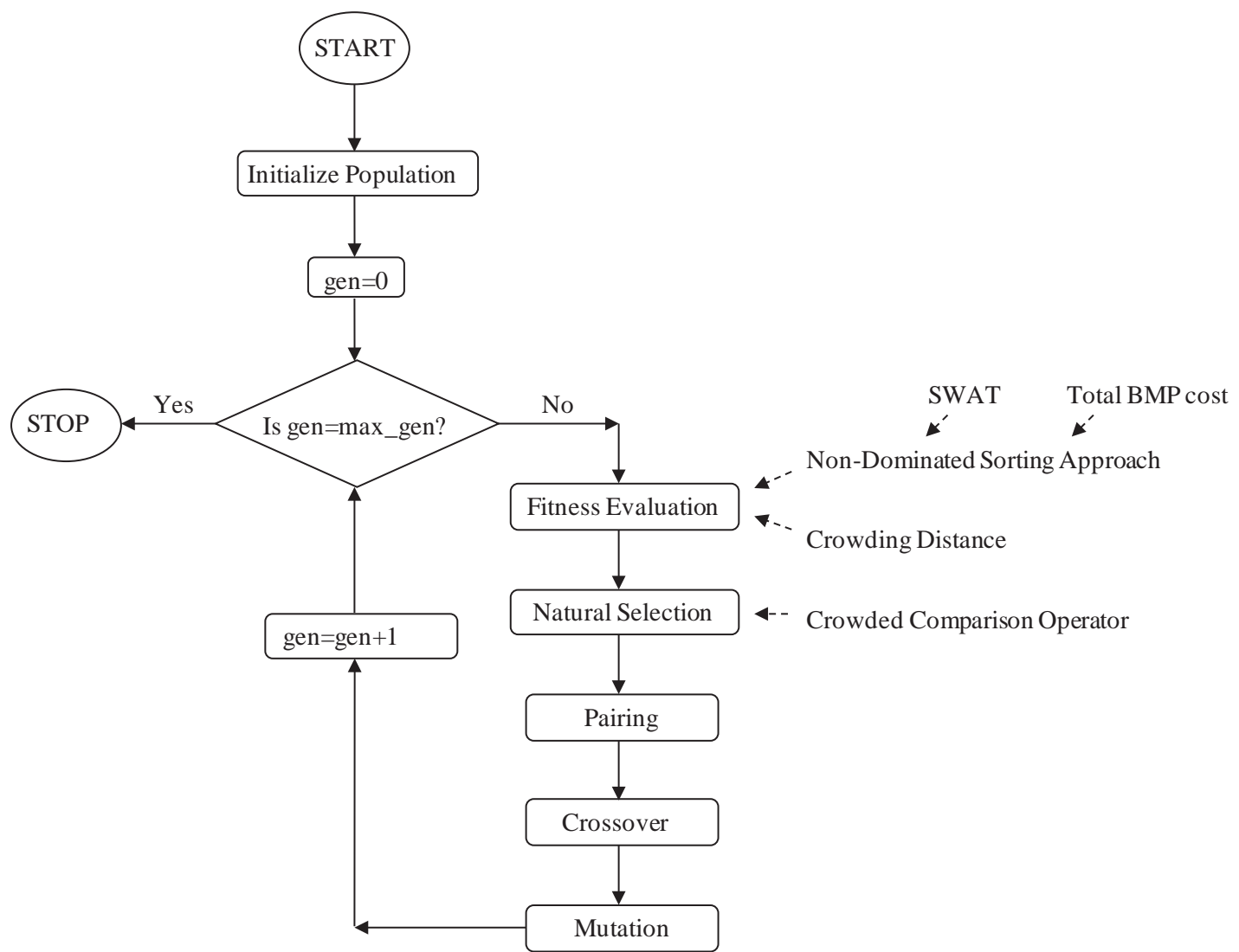

Figure 4.3. Flowchart of the NSGA-II. 


\subsection{Results of Optimization}

Two running performance metrics for evolutionary multi-objective optimizations have been suggested, namely, convergence and diversity (Deb and Jain 2002).

Table C. 1 from Appendix C and Figure 4.4 show the comparison between the pseudo Pareto front at the last generation of NSGA-II using a different number of total generations, namely $150,100,50$, and 17 , respectively, with mutation occurring in every generation except the last one (Haupt and Haupt 1998). When the total generation number increases, the spread of the solutions (i.e. the value range for the objective functions) also becomes larger, indicating that the solutions are more widely distributed in the solution space and, the diversity becomes larger visually.

Solutions provided by NSGA-II with different number of total generations seems to follow a similar trend (Figure 4.4), hence, visually the convergence of them are similar.

Based on the discussion above, visually, NSGA-II with 150 total generations provides the largest solution diversity and similar convergence when compared to NSGA-II with different number of total generations. Hence, the pseudo Pareto front at the last generation of NSGA-II with 150 total generations is selected to compare with the CEresult from targeting, as shown later in Chapter 5. 

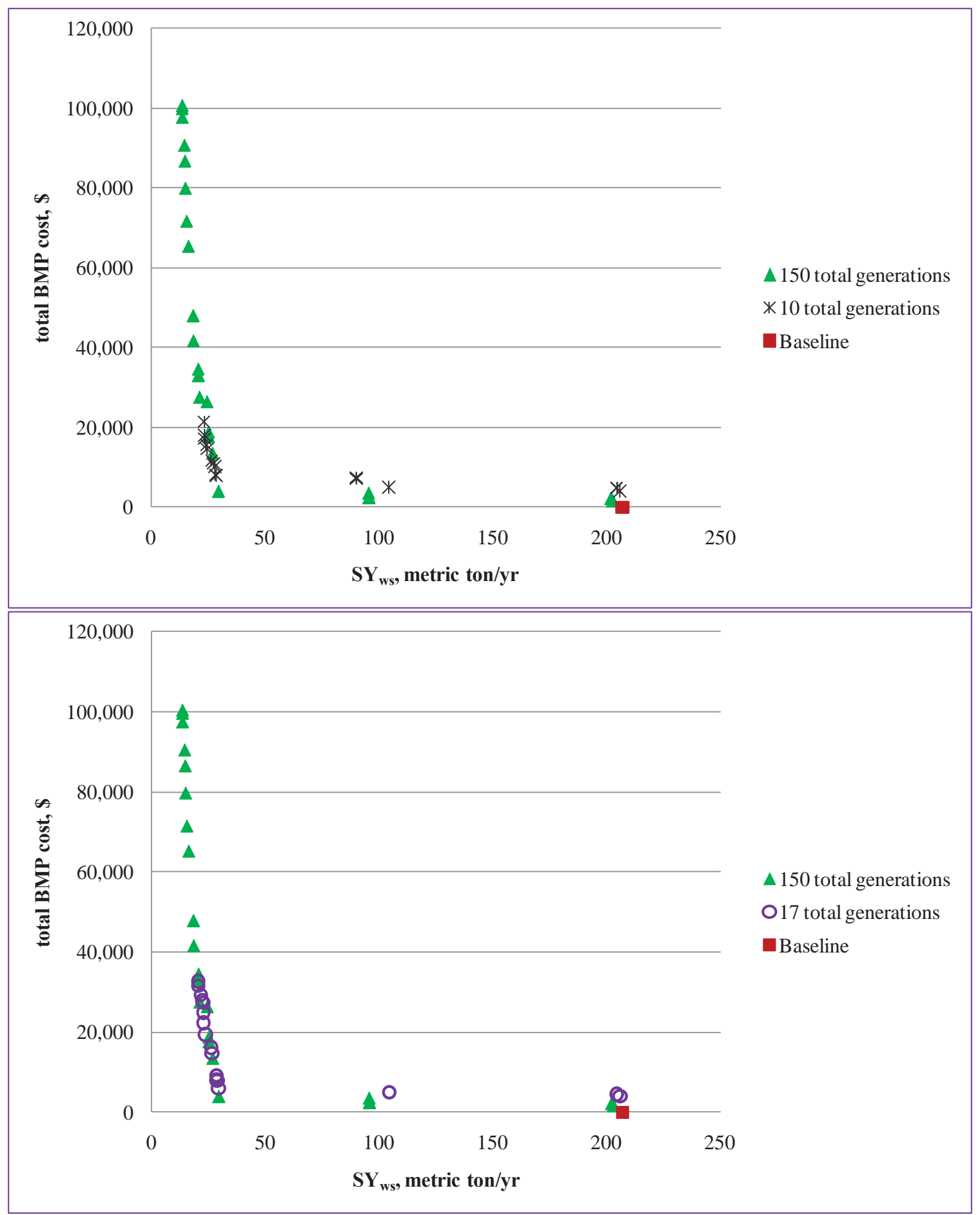


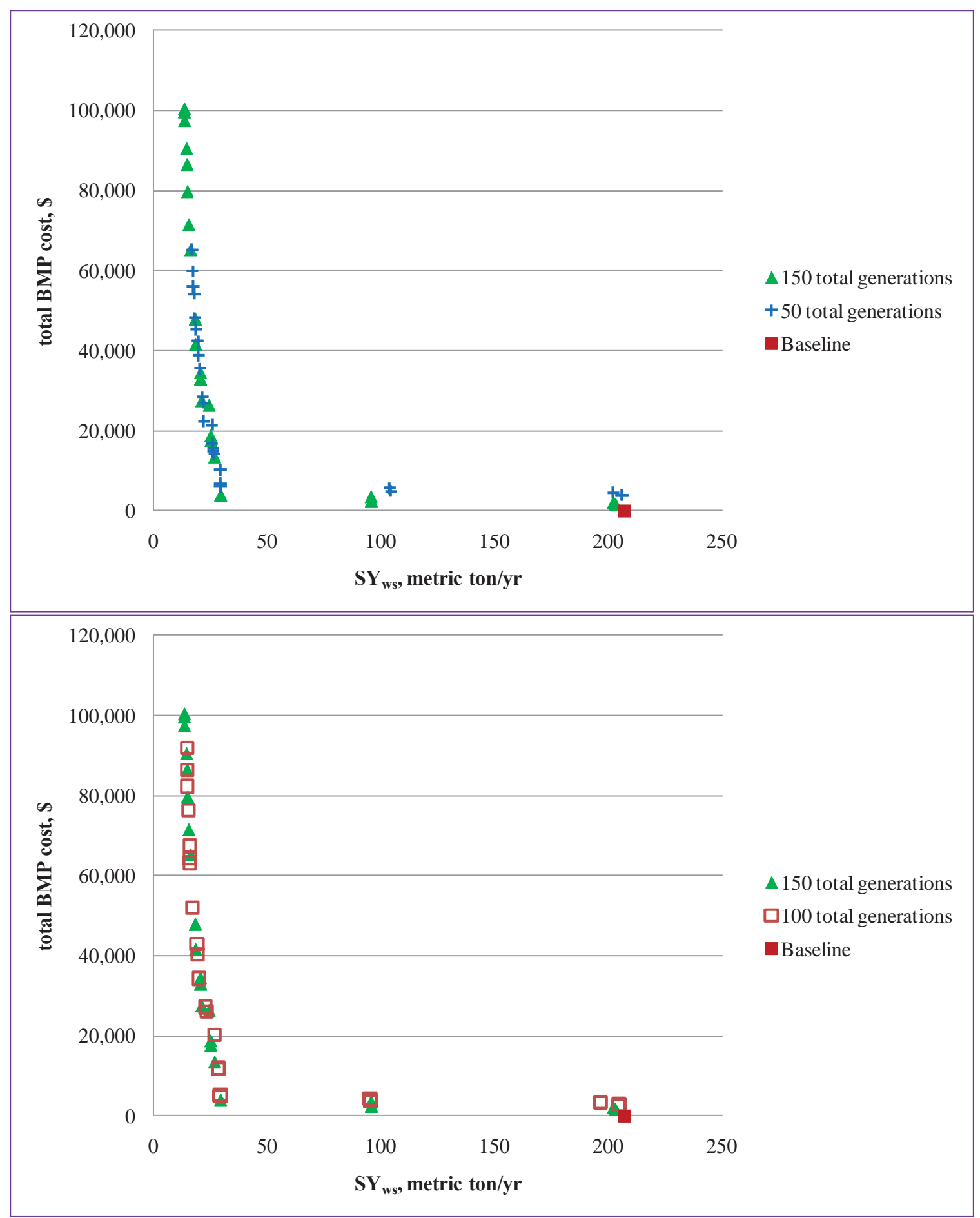




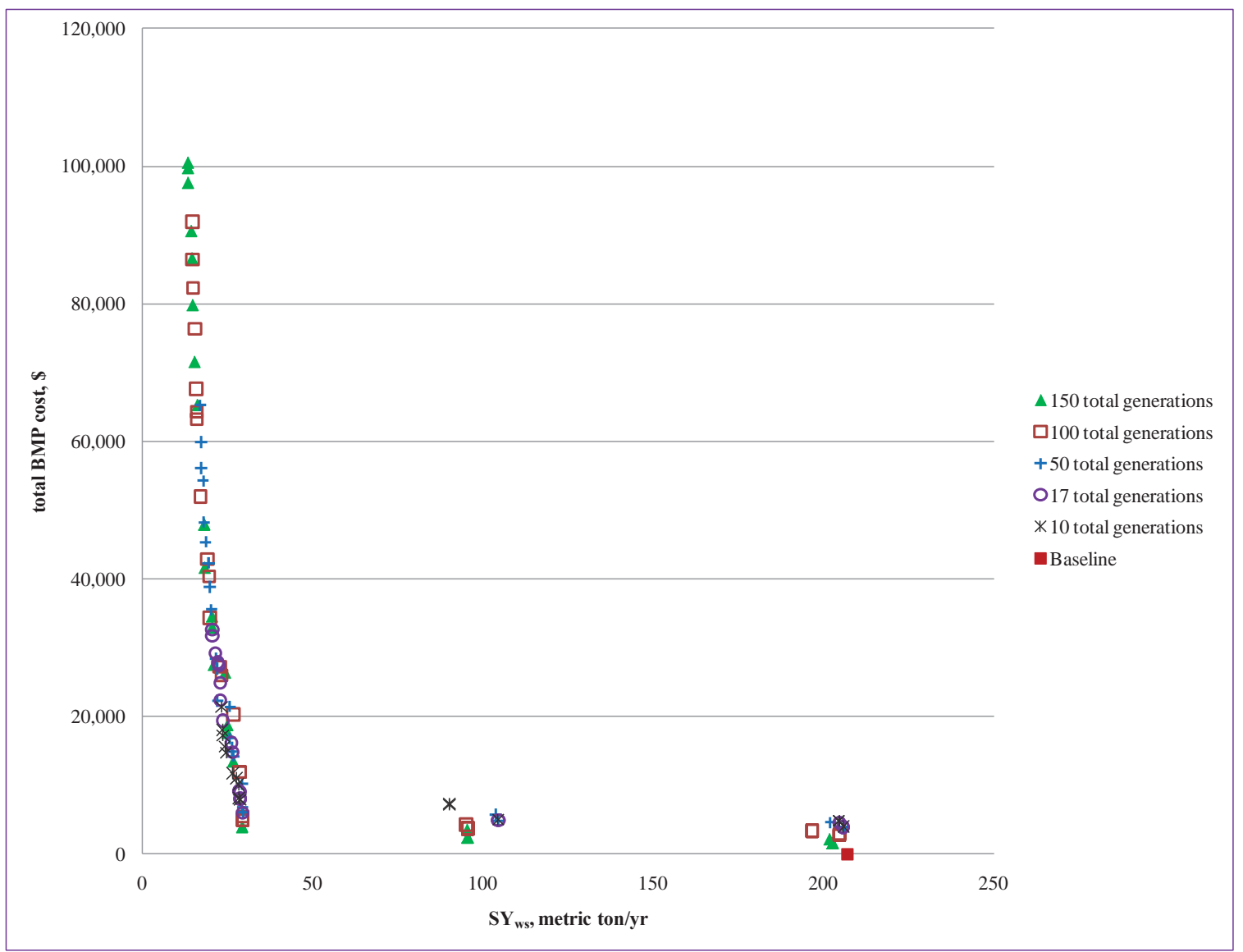

Figure 4.4. Comparison between the pseudo Pareto front at the last generation of NSGAII using different total generations.

From the pseudo Pareto front at the last generation for NSGA-II with 150 generations (Figure 4.5, and Table C.1 in Appendix C for full results), it can be seen that when watershed outlet sediment yield $\left(\mathrm{SY}_{\mathrm{ws}}\right)$ is smaller than approximately 30 metric ton/yr, the Total BMP cost increases dramatically for a small decrease in $\mathrm{SY}_{\mathrm{ws}}$, a result that is similar to that given by targeting (Figure 3.6). Above 30 metric ton/yr, there is a large increase in $\mathrm{SY}_{\mathrm{ws}}$ for a marginal cost reduction. 


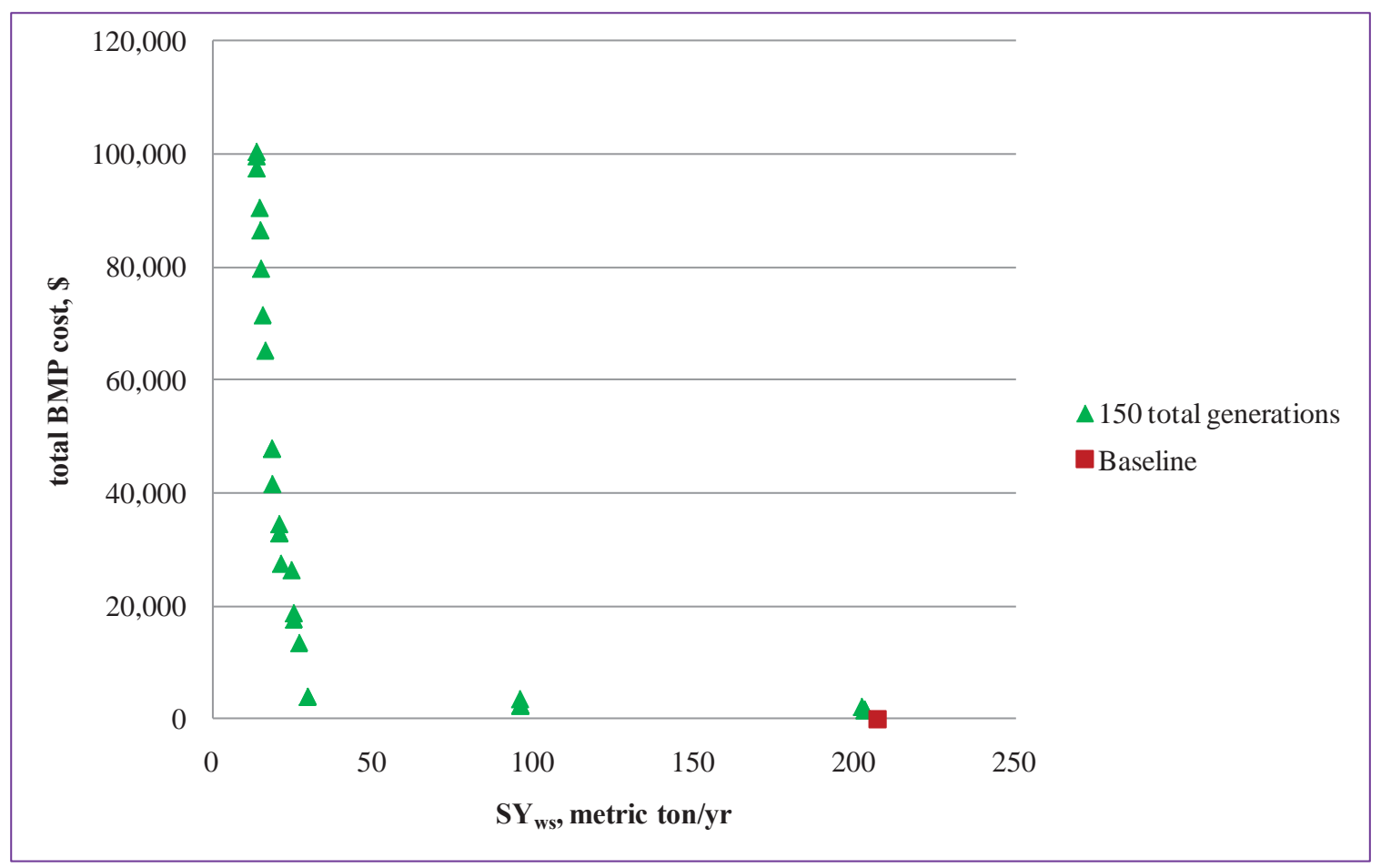

Figure 4.5. Pseudo Pareto front at the last generation of NSGA-II with 150 total generations. 


\section{Chapter 5. Comparison of Targeting and Optimization}

\section{Methods}

\subsection{Objectives}

The objective of Chapter 5 is to compare targeting and optimization. The solution fitness for the objective functions is investigated for both targeting and NSGA-II. Later, by comparing the solution and the computational time for targeting and optimization, the better of these two methods for finding the optimal cost-effective BMP allocation is decided.

\subsection{Comparison Procedure}

\subsubsection{Solution of Targeting and Optimization Methods}

In order to determine which method provides results fitting the objective functions better, the non-domination, which is the theory used by NSGA-II to select the solutions fitting the objective functions best, is applied as a comparison criterion. As described in Section 4.2.1, if all the objective functions are to be minimized, a feasible solution $x$ is said to dominate another feasible solution $y$, only if the following two conditions are both satisfied (Konak et al. 2006):

1) $\quad z_{i}(x) \leq z_{i}(y)$ for all objective functions \&

2) $\quad z_{i}(x)<z_{i}(y)$ for at least one objective function. 
Where

$z=$ Objective function, $i=1,2 \ldots$

$x=$ The dominating solution;

$y=$ The dominated solution.

If a solution is non-dominated by any other solutions (i.e. it fits the objective functions best), it belongs to the best non-dominated front $\left(F_{1}\right)$. Otherwise, a solution belonging to $F_{i}(\mathrm{i}>1)$ is dominated by other solutions from $F_{1}$ to $F_{i-1}$. The CEresult of the targeting and the pseudo Pareto front provided by the $150^{\text {th }}$ generation of the NSGA-II are investigated using the method discussed above, and the objective functions are:

1) Minimize the watershed outlet sediment yield ( $\left.S Y_{w s}\right)$;

2) Minimize total BMP cost.

For each solution from targeting as well as NSGA-II, the value will be compared with those dominating it, using the equations below (Eq. 14):

$$
\begin{aligned}
& \operatorname{difference}\left(z_{i}\left(y, x_{j}\right)\right)=z_{i}(y)-z_{i}\left(x_{j}\right) \\
& \text { percent_diff }\left(z_{i}\left(y, x_{j}\right)\right)=\frac{z_{i}(y)-z_{i}\left(x_{j}\right)}{z_{i}(y)} ; \\
& \max \left(\operatorname{difference}\left(z_{i}(y, x)\right)=\max \left(\operatorname{difference}\left(z_{i}\left(y, x_{j}\right)\right)\right), \text { for } \mathrm{j}=1,2 \ldots ;\right. \\
& \max \left(\text { percent_diff }\left(z_{i}(y, x)\right)=\max \left(\operatorname{percent} \_\operatorname{diff}\left(z_{i}\left(y, x_{j}\right)\right)\right), \text { for } \mathrm{j}=1,2 \ldots\right.
\end{aligned}
$$




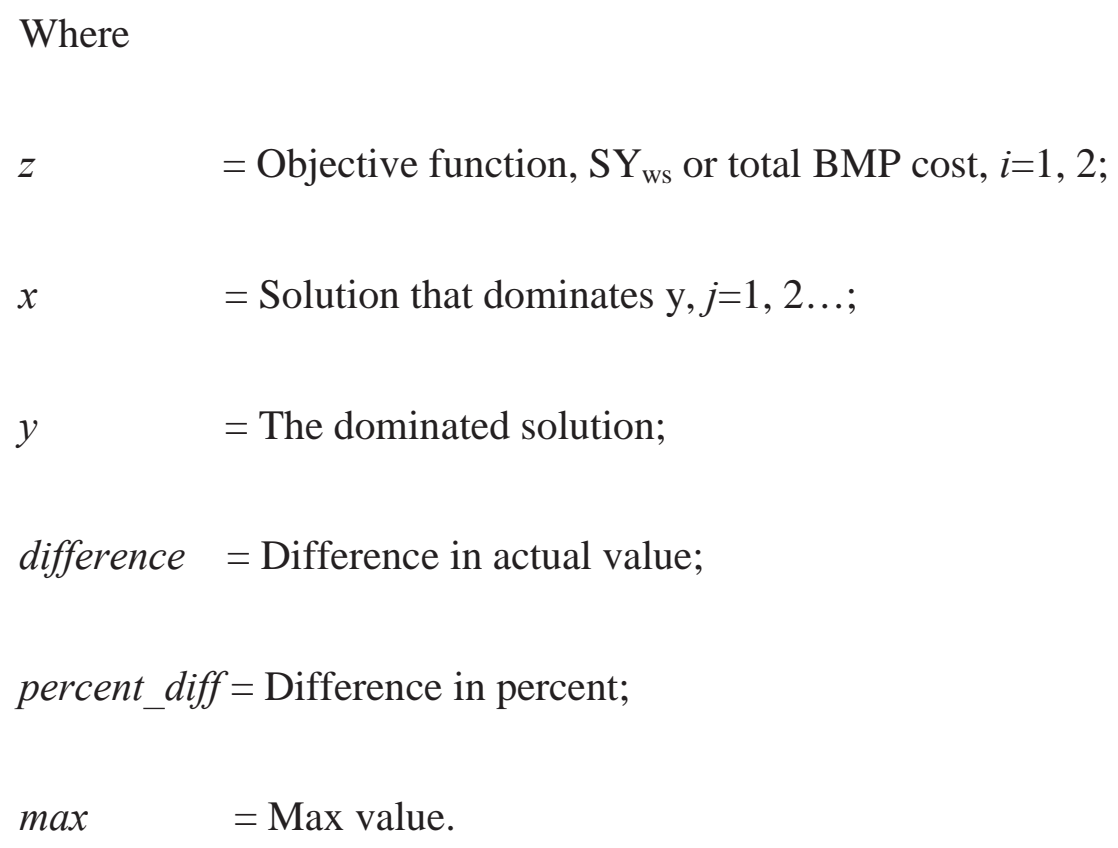

The non-dominated results (Table D.1 in Appendix D) show that almost all the solutions from the NSGA-II are dominated by those from targeting, indicating that the targeting solutions fit the objective functions better than those provided by NSGA-II. For solutions from NSGA-II, the max(difference $\left(\mathrm{SY}_{\mathrm{ws}}\right)$ ) (defined in Eq. 14) (Table D.1 in Appendix D) ranges from 98.10 to 0.23 metric ton/yr, leading to $70.09 \%$ to $1.72 \%$ in $\max \left(\right.$ percent_diff(SY $\left.\left.\mathrm{SY}_{\mathrm{ws}}\right)\right)$. Also $\max ($ difference(total BMP cost)) ranges from $\$ 16,546$ to $\$ 599$, resulting in $58.22 \%$ to $5.48 \%$ for the $\max ($ percent_diff(total BMP cost)). As shown in Figure 5.2, with the same level of total BMP cost, the solutions of targeting result in less watershed outlet sediment yield ( $\left.\mathrm{SY}_{\mathrm{ws}}\right)$ and with the same level of $\mathrm{SY}_{\mathrm{ws}}$ and the solutions of targeting result in less total BMP cost.

The only non-dominated solution of NSGA-II is with 95.5 metric ton/yr of SY $\mathrm{ws}_{\mathrm{ws}}$, and $\$ 2,536$ of total BMP cost (Figure 5.1). As mentioned in Chapter 3, targeting adds a single BMP to the BMP allocation using the order of cost-effectiveness rank (CErank) 
but does not consider other possible allocations which do not follow the ranking order.

For example, if an allocation consisting of BMPs ranking $2^{\text {nd }}$ and $4^{\text {th }}$ in the CErank costs the same amount of money as the allocation with only the $1^{\text {st }}$ ranked BMP, which allocation is better is a question unanswered by targeting. Therefore, it is possible that targeting misses an effective BMP placement combination, as apparently is the case for this one non-dominated NSGS-II solution. Besides this single point, however, the results of targeting have better fitness for the objective functions than that of the NSGA-II does.

When it comes to the non-dominated targeting solutions (Table D.1 in Appendix D), some solutions from targeting are dominated by others from targeting, and $\max \left(\right.$ difference $\left.\left(\mathrm{SY}_{\mathrm{ws}}\right)\right)$ ranges from 0.05 to 0 metric ton/yr, leading to $0.32 \%$ to $0 \%$ in $\max \left(\right.$ percent_diff $\left.\left(\mathrm{SY}_{\mathrm{ws}}\right)\right)$. Also $\max ($ difference(total BMP cost)) ranges from $\$ 9,665$ to $\$ 1$, resulting in $4.65 \%$ to $0.03 \%$ for the $\max ($ percent_diff(total BMP cost)). For $\max \left(\right.$ difference $\left.\left(\mathrm{SY}_{\mathrm{ws}}\right)\right)$, since 0.05 was so small that it may be result from rounding errors of SWAT. When it comes to the $\max ($ difference(total BMP cost)), as discussed in Section 3.4.3, the combined effect of the BMP allocation is not simply the sum of the individual effects of all the BMPs, and actually $\Delta \mathrm{SY} \mathrm{Y}_{\mathrm{ws}}$ (reduction of $\mathrm{SY}_{\mathrm{ws}}$ compared to baseline) of the former is always smaller than that of the latter. This is due to the fact that the impact of a BMP changes with the existence of other BMPs. Hence, an allocation with more BMPs added may yield the same amount of $\mathrm{SY}_{\mathrm{ws}}$ as that without, thereby leading to it's being dominated slightly by the previous solution, since the latter one costs less (e.g. $2^{\text {nd }}$ allocation is dominated by the $1^{\text {st }}$ one) . 
By comparing the spread (i.e. the value range for the objective functions) and diversity of the solutions, it is found that targeting provides a much larger range of solutions than the NSGA-II does, and a larger range provides a deeper scope and understanding of the relationship between the $\mathrm{SY}_{\mathrm{ws}}$ and the total BMP cost. Also, targeting provides $416 \mathrm{BMP}$ allocation solutions, which are more than 13 times as many as the pseudo Pareto front of the NSGA-II (Table D.1 in Appendix D) does. Hence, it can be concluded that, with respect to the solution, targeting is better that NSGA-II with 150 generations under these study conditions.

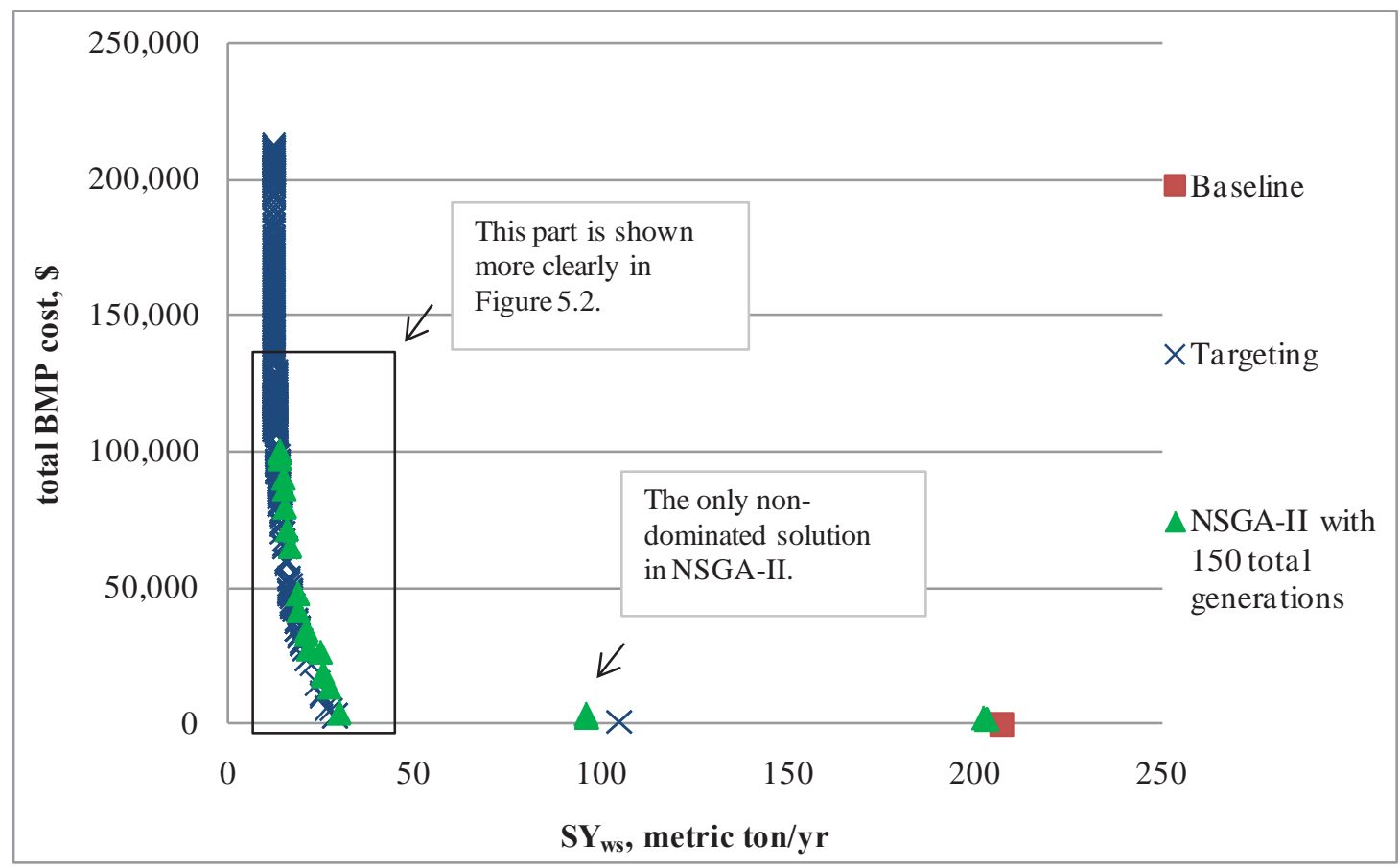

Figure 5.1. Comparison between targeting and NSGA-II (full results). 


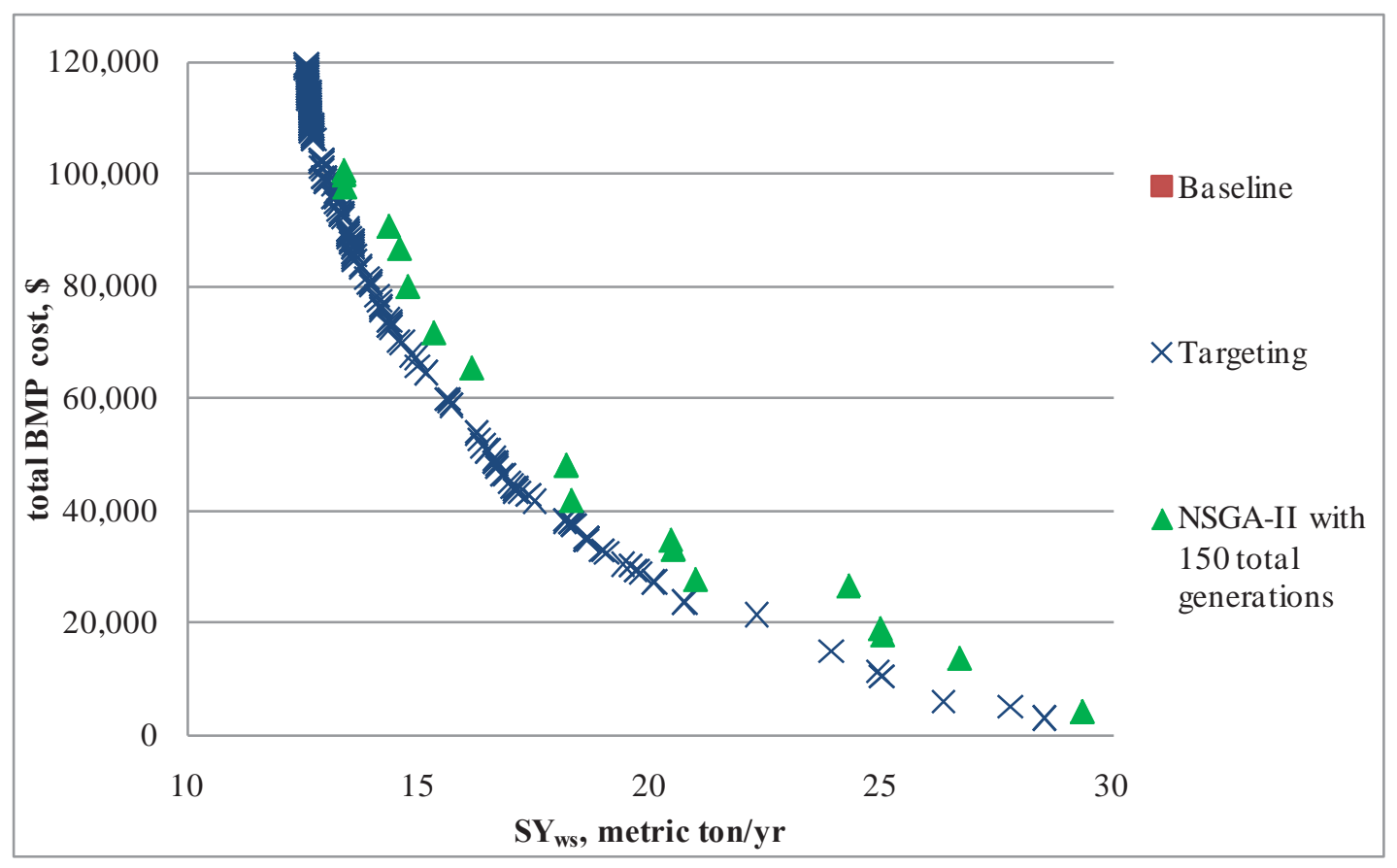

Figure 5.2. Comparison between targeting and NSGA-II (partial results, in order to show the difference beween targeting and NSGA-II more clearly).

\subsubsection{Computational Times of Targeting and Optimization Methods}

Most of the computational times for both methods are spent on SWAT simulation for evaluating the BMP performance. For this study area, a single run of SWAT for 8 years (Years 2000-2003 as warm-up period while years 2004-2007 as simulation period) needs 2 minutes on a computer of an Intel Pentium 4 Processor, or 1 minute on a computer of an Intel Core 2 Quad Processor.

The computational time for NSGA-II directly relates to the number of total generations, hence the SWAT computational time for NSGA-II with different total generations is also shown in Table 5.1. 
By comparing the computational time needed by each method, targeting appears to be a faster option, spending less than one eighth of the time that NSGA-II with 150 generations spends (Table 5.1). Even though NSGA-II with 17 generations needs similar time as targeting does, as mentioned in Section 4.4, it provides a much narrower spread of solutions (i.e. the value range for the objective functions) and much smaller diversity when compared to the NSGA-II with 150 generations, even more so if compared with the CEresult from targeting (Figure 5.3). Such a small spread will limit the NSGA-II in showing the relationship between the $\mathrm{SY}_{\mathrm{ws}}$ and the total BMP cost.

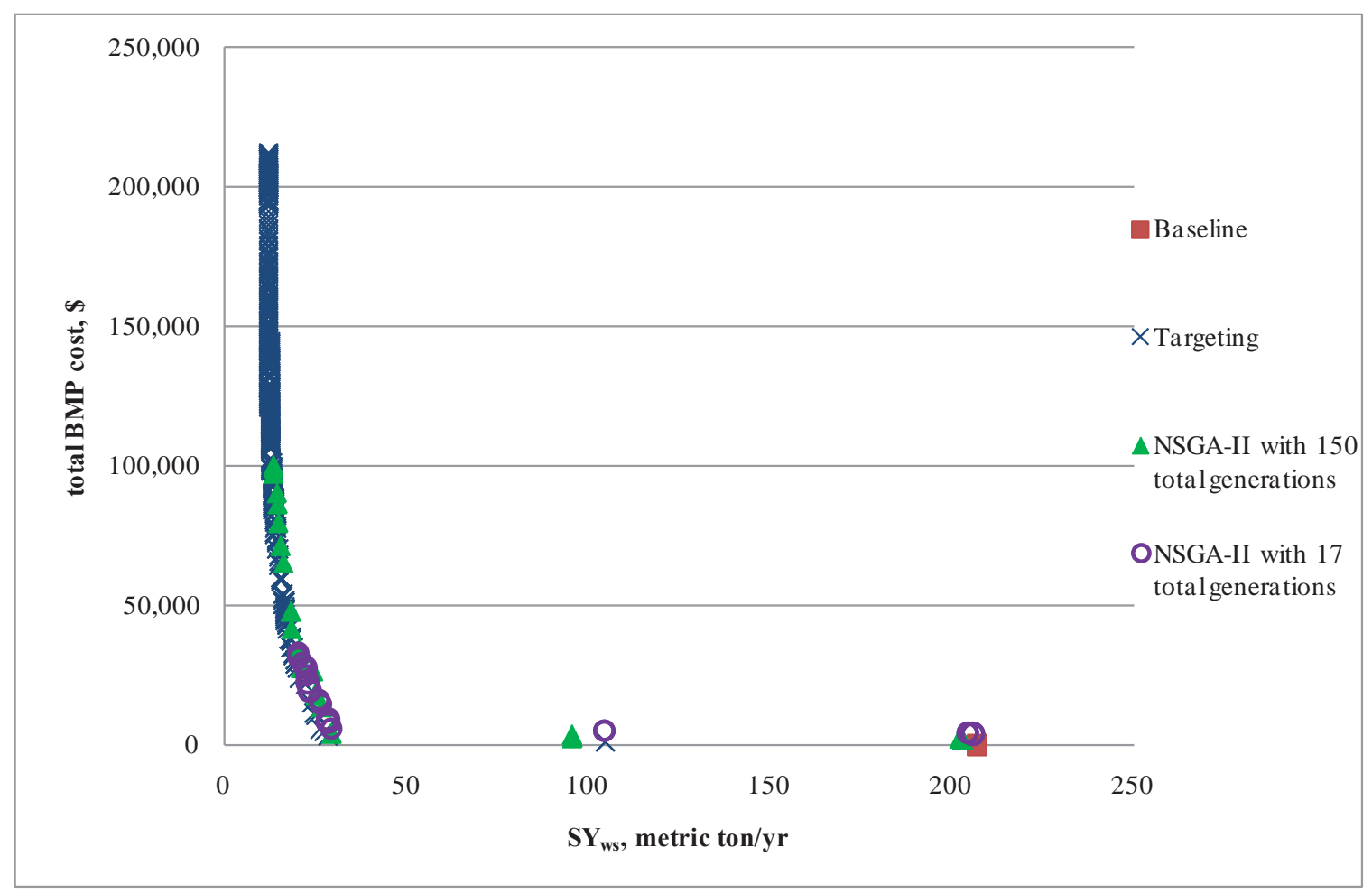

Figure 5.3. Comparison between targeting and NSGA-II with different total generations. 
Table 5.1. Comparison of the computational time for targeting and NSGA-II

\begin{tabular}{|c|c|c|c|}
\hline Method & $\begin{array}{l}\text { SWAT } \\
\text { simulation } \\
\text { times }\end{array}$ & $\begin{array}{l}\text { Time spent on the } \\
\text { SWAT**, min }\end{array}$ & Descriptions \\
\hline Targeting & 832 & 832 & $\begin{array}{l}416 \text { times for finding the cost- } \\
\text { effectiveness rank (CErank) } \\
\text { for } 208 \text { sub-watershed and } 208 \\
\text { main channel segments; } 416 \\
\text { times for modeling the cost- } \\
\text { effectiveness result (CEresult) } \\
\text { of the targeting based on the } \\
\text { CErank, by adding new BMP } \\
\text { to the BMPs allocation one at a } \\
\text { time. }\end{array}$ \\
\hline $\begin{array}{l}\text { NSGA-II with } \\
150 \text { generations }\end{array}$ & 7395 & 7395 & \multirow{5}{*}{$\begin{array}{l}\text { The NSGS-II includes } 1 \text { initial } \\
\text { generation, pluses } 150,100,50 \text {, } \\
\text { 17, and } 10 \text { generations, } \\
\text { respectively (Table } 4.1 \text { ). }\end{array}$} \\
\hline $\begin{array}{l}\text { NSGA-II with } \\
100 \text { generations }\end{array}$ & 4945 & 4945 & \\
\hline $\begin{array}{l}\text { NSGA-II with } \\
50 \text { generations }\end{array}$ & 2472 & 2472 & \\
\hline $\begin{array}{l}\text { NSGA-II with } \\
17 \text { generations }\end{array}$ & 849 & 849 & \\
\hline $\begin{array}{l}\text { NSGA-II with } \\
10 \text { generations }\end{array}$ & 502 & 502 & \\
\hline $\begin{array}{l}\text { Complete } \\
\text { Enumeration }\end{array}$ & $2^{416}$ & $2^{416} \mathrm{~min}=3.22 * 10^{119} \mathrm{yr}$ & $\begin{array}{l}\text { The complete enumeration is } \\
\text { practically infeasible, since it } \\
\text { needs too much time to finish. }\end{array}$ \\
\hline
\end{tabular}

** SWAT run on a computer with the Intel Core 2 Quad Processor. 


\subsubsection{Uncertainty of Targeting and Optimization Methods}

Both of these two methods contain uncertainties in the ability of finding the optimal BMP allocation.

For targeting, it adds a single BMP to the BMP allocation using the rank (CErank) of cost-effectiveness but does not consider other possible allocations which do not follow the rank order, thereby, making it possible that targeting misses an effective BMP placement combination, as discussed previously in Chapter 3 and Section 5.2.1.

For NSGA-II, the effectiveness of optimizing the BMP allocation depends on the value selected for its parameters, such as the total number of generations, population size, mutation rate, and so on (Table 4.1). One way to find out an effective/optimal parameter combination is to perform a sensitivity analysis by changing the parameters and comparing the results. This potentially laborious procedure is not needed, however by targeting. 


\subsection{Conclusions of the Compasion of Targeting and}

\section{Optimization Methods}

By comparing the solution fitness (i.e. non-domination in this study) of targeting and NSGA-II, it is found that nearly all the solutions from the pseudo Pareto front of NSGAII are dominated by those from the CEresult of targeting; proving that targeting provides better BMP allocation solutions. Also, targeting provides more than 13 times the amount of solutions with a larger spread of the objective function values, and needs less than one eighth of the SWAT computational time than the NSGA-II with 150 generations does. Hence, targeting is a better method than the NSGA-II for finding the optimal costeffective BMPs allocation under the conditions studied here. 


\section{Chapter 6. Application of the Targeting Based on Cost}

Targeting based on cost has been proven to be a better method than the NSGA-II for finding the optimal cost-effective BMP allocation. The results of targeting provide detailed information about the watershed outlet sediment yield ( $\left.\mathrm{SY}_{\mathrm{ws}}\right)$ and the corresponding total BMP costs (Figure 6.1), which can assist the decision maker to find the BMP allocation leading to the most pollution reduction for a given cost.

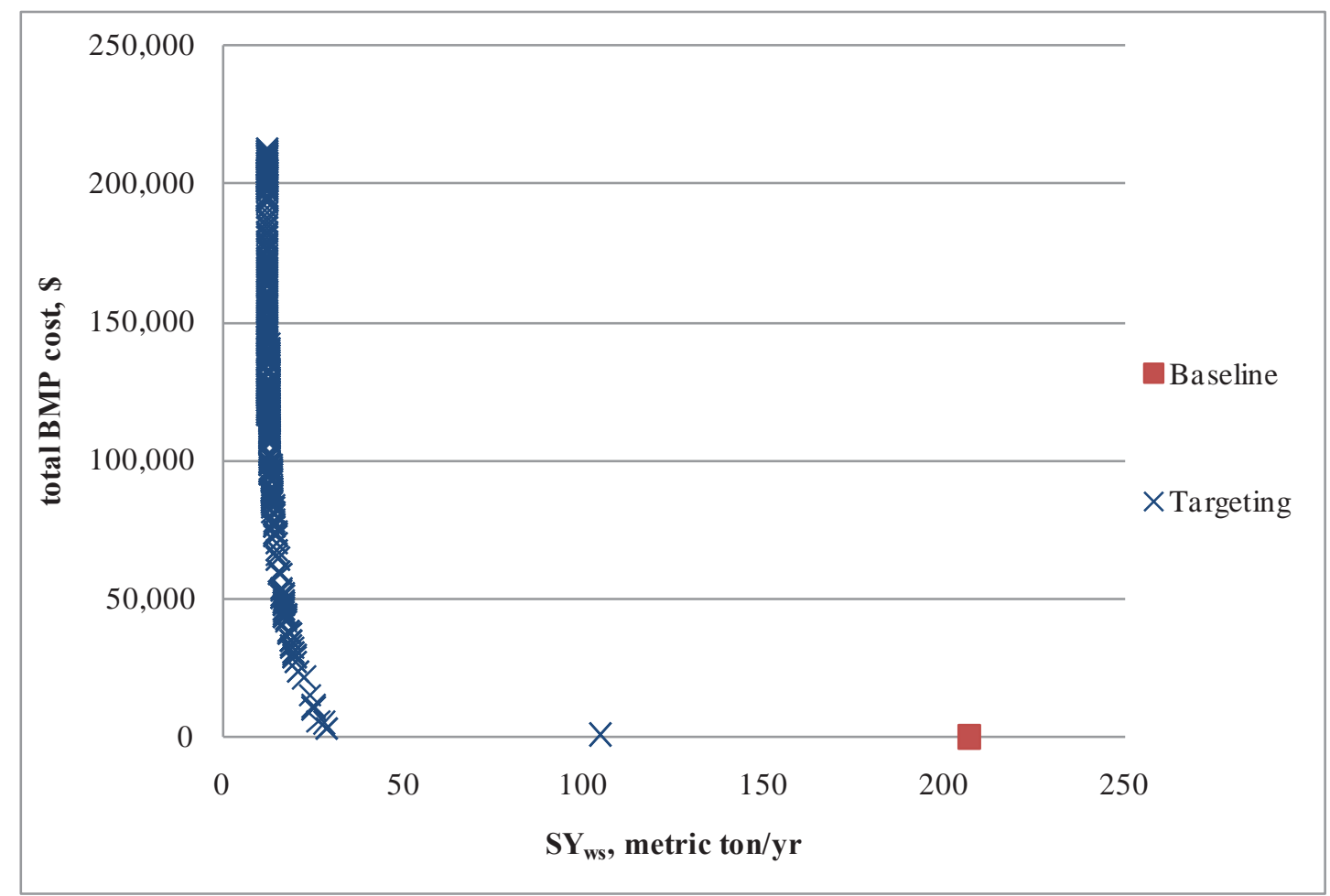

Figure 6.1. Results of BMP (5-m filter strips and grassed waterways) allocation from targeting based on cost. 


\section{Chapter 7. Summary and Future Work}

In this study, two methodologies, targeting and Non-dominated Sorting Genetic

Algorithm II (NSGA-II), have been explored to optimize the cost-effectiveness of BMP allocation in reducing the watershed outlet sediment yield. Both methodologies have been applied to an agriculture-dominant watershed with 3345.49ha in Lower Michigan. For the simplicity and coverage for both on-land and in-stream BMPs, filter strips and grassed waterways are the two types of BMP considered in this study. A watershed scale

model, Soil and Water Assessment Tool (SWAT) has been used to evaluate the impact of the BMP placement on the sediment yield. The results and computational time of both methods have been compared, leading to the conclusion that targeting is better than NSGA-II in finding the optimal cost-effective BMP allocation under these study conditions.

For future study, other types of BMPs could be considered and for a larger study area. In addition to sediment, other kinds of pollution, such as nutrients, could be also evaluated. The observed data of pollution could be used to calibrate the SWAT model. These two methodologies, targeting and NSGA-II, could be applied in solving other types of optimizing problem, such as the cost-effective design of the pipe networks. 


\section{Reference List}

Abbaspour KC. 2008. SWAT-CUP2: SWAT Calibration and Uncertainty Programs - A User Manual.

Abbaspour KC, Yang J, Maximov I, Siber R, Bogner K, Mieleitner J, Zobrist J, Srinivasan R. 2007. Modelling hydrology and water quality in the prealpine/alpine Thur watershed using SWAT. Journal of Hydrology 333(Compendex):413-430.

Arabi M, Frankenberger JR, Engel BA, Arnold JG. 2008. Representation of agricultural conservation practices with SWAT. Hydrological Processes 22(16):3042-3055.

Arabi M, Govindaraju RS, Hantush MM. 2006. Cost-effective allocation of watershed management practices using a genetic algorithm. Water Resources Research 42(Compendex).

Bingner RL, Theurer FD, Yuan Y. 2009. AnnAGNPS technical processes documentation version 5.0.

Borah DK, Bera M. 2003. Watershed-scale hydrologic and nonpoint-source pollution models: Review of mathematical bases. Transactions of the American Society of Agricultural Engineers 46(Compendex):1553-1566.

Bouraoui F, Dillaha TA. 1996. ANSWERS-2000: runoff and sediment transport model. Journal of Environmental Engineering 122(Compendex):493-502. 
Bracmort KS, Arabi M, Frankenberger JR, Engel BA, Arnold JG. 2006. Modeling longterm water quality impact of structural BMPs. Transactions of the ASABE 49(Compendex):367-374 .

Coello Coello CA. 2006. Evolutionary multi-objective optimization: A historical view of the field. IEEE Computational Intelligence Magazine 1(Compendex):28-36.

Deb K, Jain S. Running Performance Metrics for Evolutionary Multi-Objective Optimization. Proceedings of the 4th Asia-Pacific Conference on Simulated Evolution and Learning (SEAL'02); November 2002 2002: Nanyang Technical University, Orchid Country Club, Singapore. p. 13-20.

Deb K, Pratap A, Agarwal S, Meyarivan T. 2002. A fast and elitist multiobjective genetic algorithm: NSGA-II. Evolutionary Computation, IEEE Transactions on 6(2):182197.

DEQ. 2011. DEQ Guidebook of BMPs. In: DEQ, editor.

EPA. 2004. National Water Quality Inventory: Report to Congress, 2004 Reporting Cycle:Findings. In: EPA, editor.

Haupt RL, Haupt SE. 1998. Practical genetic algorithms. Wiley.

Kaini P, Artita K, Nicklow JW. Designing BMPs at a watershed-scale using SWAT and a genetic algorithm. World Environmental and Water Resources Congress 2008: Ahupua'a - Proceedings of the World Environmental and Water Resources Congress 2008. World Environmental and Water Resources Congress 2008: 
Ahupua'a, May 12, 2008 - May 16, 2008; 2008; Honolulu, HI, United states: American Society of Civil Engineers. p. Environmental and Water Resources Institute of ASCE.

Konak A, Coit DW, Smith AE. 2006. Multi-objective optimization using genetic algorithms: A tutorial. Reliability Engineering and System Safety 91(Compendex):992-1007.

Maringanti C, Chaubey I, Popp J. 2009. Development of a multiobjective optimization tool for the selection and placement of best management practices for nonpoint source pollution control. Water Resources Research 45(Compendex).

McCully P. 1996. Silenced rivers: the ecology and politics of large dams. Zed Books.

Moriasi DN, Arnold JG, Van Liew MW, Bingner RL, Harmel RD, Veith TL. 2007. Model evaluation guidelines for systematic quantification of accuracy in watershed simulations. Transactions of the ASABE 50(Compendex):885-900.

Nash JE, Sutcliffe JV. 1970. River flow forecasting through conceptual models part I -- A discussion of principles. Journal of Hydrology 10(3):282-290.

Neitsch SL, Arnold JG, Kiniry JR, Williams JR. 2005. Soil and Water Assessment Tool Theoretical Documentation Version 2005.

Niu Z, Sun G, McNulty SG, Xie M, Byne W. 2001. Applying ANSWERS-2000 to simulate BMP effects on sediment and runoff from two watersheds in the Three Gorges area, southern China. Soil Erosion Research for the 21st Century:653-656. 
Osterkamp WR, Heilman P, Lane LJ. 1998. Economic considerations of a continental sediment-monitoring program. International Journal of Sediment Research 13(Compendex):12-24.

Parajuli PB, Mankin KR, Barnes PL. 2008. Applicability of targeting vegetative filter strips to abate fecal bacteria and sediment yield using SWAT. Agricultural Water Management 95(Compendex):1189-1200.

Parajuli PB, Nelson NO, Frees LD, Mankin KR. 2009. Comparison of AnnAGNPS and SWAT model simulation results in USDA-CEAP agricultural watersheds in south-central Kansas. Hydrological Processes 23(Compendex):748-763.

Pedersen GKM, Goldberg DE. 2004. Dynamic Uniform Scaling for Multiobjective Genetic Algorithms. Genetic and Evolutionary Computation - GECCO 2004. Springer Berlin / Heidelberg. p. 11-23-23.

Saleh A, Du B. 2004. Evaluation of SWAT and HSPF within BASINS program for the upper North Bosque River watershed in central Texas. Transactions of the American Society of Agricultural Engineers 47(Compendex):1039-1049.

SCS. 1972. Section 4: Hydrology. National Engineering Handbook. Soil Conservation Service.

Sheshukov A, Daggupati P. 2010. SSURGO Processing Tool User Guide. 
Srivastava P, Hamlett JM, Robillard PD, Day RL. 2002. Watershed optimization of best management practices using AnnAGNPS and a genetic algorithm. Water Resources Research 38(Compendex):31-314.

Tuppad P, Douglas-Mankin KR, McVay KA. 2010. Strategic targeting of cropland management using watershed modeling. Agricultural Engineering International: CIGR Journal 12.

Williams JR. 1995. The EPIC model. Computer models of watershed hydrology. Water Resources Publications. p. 909-1000.

WINCHELL M, SRINIVASAN R, LUZIO MD, ARNOLD J. 2009. ARCSWAT 2.1.5 INTERFACE FOR SWAT2005 USER'S GUIDE.

Wood PJ, Armitage PD. 1997. Biological effects of fine sediment in the lotic environment. Environmental Management 21(Compendex):203-217.

Yang J, Reichert P, Abbaspour KC, Xia J, Yang H. 2008. Comparing uncertainty analysis techniques for a SWAT application to the Chaohe Basin in China. Journal of Hydrology 358(Compendex):1-23. 


\section{Appendix}

Appendixes A, B, C, D and E are in the Excel file "Appendix".

1 Appendix A. Tables for Criteria Comparison

Appendix A contains five tables:

1) Table A.1. Rank A for filter strips;

2) Table A.2. Rank $B$ for filter strips;

3) Table A.3. Rank $C$ for filter strips;

4) Table A.4. Rank C for grassed waterways;

5) Table A.5. 4-yr average difference between SEDIN and SEDOUT for each main channel segments.

2 Appendix B. Tables for Targeting Based on Cost-Effectiveness

Appendix B contains two tables:

1) Table B.1. CErank for both filter strips and grassed waterways;

2) Table B.2. CEresult.

3 Appendix C. Table for the pseudo Pareto Front of NSGA-II

Appendix $\mathrm{C}$ includes one table: 
1) Table C.1. Results of the last generation of NSGA-II with different total

generations.

4 Appendix D. Table for Comparison of Targeting and NSGA-II

Appendix D contains one table:

1) Table D.1. Non-domination of solutions from both targeting and NSGA-II.

5 Appendix E. Table for the Term Used in This Study

Appendix E contains one table:

1) Table E.1. Explanations for the term used in this study. 